\title{
Conditional Ablation and Recovery of Forebrain Neurogenesis in the Mouse
}

\author{
BENJAMIN H. SINGER, ${ }^{1,2}$ EMILY M. JUTKIEWICZ, ${ }^{3}$ CYNTHIA L. FULLER, ${ }^{1,2}$ ROBIN J. LICHTENWALNER, ${ }^{1,2}$ \\ HELEN ZHANG, ${ }^{1,2}$ ALAN J. VELANDER, ${ }^{1,2}$ XIANGQUAN LI, ${ }^{4}$ MARGARET E. GNEGY, ${ }^{2,3}$ \\ CHARLES F. BURANT, ${ }^{4}$ AND JACK M. PARENT ${ }^{1,2 *}$ \\ ${ }^{1}$ Department of Neurology, University of Michigan Medical School, Ann Arbor, Michigan 48109 \\ ${ }^{2}$ Neuroscience Program, University of Michigan Medical School, Ann Arbor, Michigan 48109 \\ ${ }^{3}$ Department of Pharmacology, University of Michigan Medical School, Ann Arbor, Michigan 48109 \\ ${ }^{4}$ Department of Internal Medicine, University of Michigan Medical School, Ann Arbor, Michigan 48109
}

\begin{abstract}
Forebrain neurogenesis persists throughout life in the rodent subventricular zone (SVZ) and hippocampal dentate gyrus (DG). Several strategies have been employed to eliminate adult neurogenesis and thereby determine whether depleting adult-born neurons disrupts specific brain functions, but some approaches do not specifically target neural progenitors. We have developed a transgenic mouse line to reversibly ablate adult neural stem cells and suppress neurogenesis. The nestin-tk mouse expresses herpes simplex virus thymidine kinase (tk) under the control of the nestin 2nd intronic enhancer, which drives expression in neural progenitors. Administration of ganciclovir (GCV) kills actively dividing cells expressing this transgene. We found that peripheral GCV administration suppressed SVZ-olfactory bulb and DG neurogenesis within 2 weeks but caused systemic toxicity. Intracerebroventricular GCV infusion for 28
\end{abstract}

days nearly completely depleted proliferating cells and immature neurons in both the SVZ and DG without systemic toxicity. Reversibility of the effects after prolonged GCV infusion was slow and partial. Neurogenesis did not recover 2 weeks after cessation of GCV administration, but showed limited recovery 6 weeks after GCV that differed between the SVZ and DG. Suppression of neurogenesis did not inhibit antidepressant responsiveness of mice in the tail suspension test. These findings indicate that SVZ and DG neural stem cells differ in their capacity for repopulation, and that adult-born neurons are not required for antidepressant responses in a common behavioral test of antidepressant efficacy. The nestin-tk mouse should be useful for studying how reversible depletion of adult neurogenesis influences neurophysiology, other behaviors, and neural progenitor dynamics. J. Comp. Neurol. 514:567-582, 2009.

○ 2009 Wiley-Liss, Inc.

Indexing terms: subventricular zone; dentate gyrus; neural stem cell; antidepressant; depression; tail suspension test

Forebrain neurogenesis persists into adulthood in the mammalian subventricular zone (SVZ) adjacent to the lateral ventricle and the subgranular zone (SGZ) of the hippocampal dentate gyrus (Altman and Das, 1965; Altman, 1969a,b; Cameron et al., 1993; Luskin, 1993; Lois and Alvarez-Buylla, 1994; Kuhn et al., 1996; Eriksson et al., 1998). Neural progenitors in the SVZ give rise to neuroblasts, which migrate tangentially along the rostral migratory stream (RMS) to the olfactory bulb and differentiate into interneurons (Luskin, 1993, 1998; Lois and Alvarez-Buylla, 1994). Neuroblasts generated in the SGZ migrate radially a short distance into the dentate granule cell (DGC) layer and differentiate into granule cells (Cameron et al., 1993; Kuhn et al., 1996).

Although evidence indicates that adult-generated olfactory bulb and hippocampal neurons functionally incorporate into existing neural circuits (Lledo and Lagier, 2006; Gheusi and Lledo, 2007; Ge et al., 2008), the biological role of adult-born neurons in the healthy and diseased brain remains unclear. In the SVZ-olfactory bulb pathway, odor enrichment increases the survival and excitability of adult-generated olfactory bulb neurons and enhances olfactory memory performance (Rochefort et al., 2002; Rochefort and Lledo, 2005; Magavi et al., 2005; Mandairon et al., 2006a; Alonso et al., 2006), but odor deprivation has the opposite effect (Corotto et al., 1994; Man-

Grant sponsor: National Institute of Neurological Disorders and Stroke; Grant number: T32 NS007222; Grant sponsor: National Institute of Child Health and Human Development; Grant number: HD044775.

*Correspondence to: Jack M. Parent, Department of Neurology, University of Michigan Medical School, Ann Arbor, MI 48109.

E-mail: parent@med.umich.edu

Received 19 September 2008; Revised 18 December 2008; Accepted 24 February 2009

DOI 10.1002/cne.22052

Published online March 18, 2009 in Wiley InterScience (www.interscience. wiley.com). 
dairon et al., 2003, 2006b; Enwere et al., 2004). Similarly, environmental enrichment and exercise increase DGC neurogenesis (van Praag et al., 1999; Kempermann et al., 2002; Brown et al., 2003), whereas aging and stress reduce the addition of new cells (Gould et al., 1991, 1997; Kuhn et al., 1996). Many different brain insults increase SVZ and DGC neurogenesis in the adult (reviewed in Lichtenwalner and Parent, 2006), underscoring the possibility that persistent neurogenesis may be useful for restorative therapy after brain injury.

Neurogenesis in the adult may also play a role in the pathophysiology and treatment of mood disorders, such as anxiety and depression (for review, see Elder et al., 2006; Schmidt and Duman, 2007). Some animal models of depression have reduced proliferation of neuronal precursors (Chen et al., 2006; Jaako-Movits et al., 2006; Lau et al., 2007; Surget et al., 2008) and conversely, chronic antidepressant treatment may enhance cell proliferation and adult neurogenesis (Santarelli et al., 2003; Perera et al., 2007; Surget et al., 2008). Although studies of the biology of adult neurogenesis support a role for adult-born neurons in olfactory bulb and hippocampal function, the implications are limited by their correlative nature.

To explore whether adult-born neurons are necessary for aspects of brain function, several strategies have been employed for suppressing neurogenesis (Doetsch et al., 1999; Gheusi et al., 2000; Mizumatsu et al., 2003; Morshead et al., 2003; Koizumi et al., 2006; Zhang et al., 2008). Results of these studies suggest that adult neurogenesis is necessary for some, but not all, processes correlated to the birth and survival of adult-born neurons (Shors et al., 2001; Snyder et al., 2001; Santarelli et al., 2003; Saxe et al., 2006). Indeed, manipulation of adult neurogenesis has shown that addition of cells to the adult brain is not necessary for the performance of some behaviors linked to neurogenesis (Schellinck et al., 2004; Meshi et al., 2006). Treatment with antimitotic drugs (Doetsch et al., 1999; Shors et al., 2001) or brain irradiation (Snyder et al., 2001; Mizumatsu et al., 2003) are potent methods for the reduction of neurogenesis. These approaches are not specific for adult-born neurons, however, as they target all dividing cells and thus may alter essential elements of the neurovascular microenvironment and also induce inflammatory responses. Studies using traditional knockout of genes essential for neurogenesis also have proved useful, but their interpretations may be limited by widespread abnormalities of brain structure or compensatory effects elicited during development (Gheusi et al., 2000; Koizumi et al., 2006).

The herpes simplex virus thymidine kinase (HSV-tk) gene has been used successfully as a suicide gene that is toxic to actively proliferating cells (Cheng et al., 1983; Heyman et al., 1989; Bush et al., 1999). Using neural progenitor-specific gene regulatory elements to drive expression of HSV-tk allows specific, temporally controlled ablation of adult neurogenesis. In the presence of the antiviral drug ganciclovir (GCV), HSV-tk produces toxic metabolites that disrupt DNA synthesis and result in the death of dividing cells. Transgenic mice expressing HSV-tk from the glial fibrillary acidic protein (GFAP) promoter have been used to explore both the identity of neural progenitors in the brain (Morshead et al., 2003; Garcia et al., 2004) and the role of adult neurogenesis in memory and response to antidepressant drugs (Santarelli et al., 2003; Meshi et al., 2006; Saxe et al., 2006,2007). However, the GFAP-tk mouse mounts an altered response to brain injury (Bush et al.,
1999), and expression of GFAP outside the central nervous system results in systemic toxicity following GCV administration (Bush et al., 1998).

Bearing in mind the goal of ablating adult neurogenesis without altering the brain's response to injury and disease, or producing systemic toxicity that might affect behavioral performance, we have generated a transgenic mouse expressing HSV-tk from the 2nd intronic enhancer of the intermediate filament gene nestin. Nestin is expressed by neural progenitor cells in both the SVZ and SGZ (Yamaguchi et al., 2000; Maslov et al., 2004; Ernst and Christie, 2005). The second intronic enhancer element is sufficient to direct gene expression during constitutive neurogenesis, but not during the response to brain injury (Johansson et al., 2002). Thus, the nestin-tk mouse may be particularly useful for studying the role of adult neurogenesis in physiology, behavior, and regeneration after brain injury. Here we characterize the loss of cellular proliferation and depletion of immature, adult-born neurons in the nestin-tk mouse forebrain after systemic or intracerebroventricular (ICV) administration of GCV. Administration of GCV by the ICV route results in sustained, but partially reversible, ablation of adult-born neurons in healthy, adult mice. Suppression of neurogenesis in this model, moreover, does not inhibit imipramine responsiveness of mice in the tail suspension test, suggesting that adult-born neurons are not required for antidepressant-like effects in this behavioral paradigm.

\section{MATERIALS AND METHODS Animals}

The tk gene from HSV type 1, with the DNA sequence of the viral gene modified by humanizing the usage codon and eliminating all the CpGs (pMod-TK, Invitrogen, Carlsbad, CA), was fused downstream of a minimal TK promoter element followed by a 1.8-kb fragment of the 2 nd intronic nestin enhancer (Fig. 1A) (Yaworsky and Kappen, 1999). The insert was purified for pronuclear injection by the Transgenic Core at the University of Michigan Diabetes Research and Training Center, and 13 founders from two separate injections were generated on an FVB background. The mice appeared healthy with normal growth and reproduction. Mice were genotyped by polymerase chain reaction (PCR), and nestin-tk ${ }^{+}$mice and wild-type littermate controls were 8-12 weeks of age at the onset of treatment. All procedures involving animals were approved by the University Committee on the Use and Care of Animals of the University of Michigan.

\section{Neurosphere cultures}

Neurosphere (NS) cultures were prepared as previously described (Wang et al., 2005). Briefly, postnatal day 40 (P40) nestin- $\mathrm{tk}^{+}$mice and wild-type FVB littermates were anesthetized with $\mathrm{CO}_{2}$, the brains were removed and cut into 2-mmthick coronal blocks, and the lateral SVZ was dissected, minced, and dissociated with trypsin. Approximately 3-8 $\times$ $10^{4} \mathrm{SVZ}$ cells per $60-\mathrm{mm}$ dish were cultured in Dulbecco's modified Eagle's medium (DMEM)/F12 (1:1, Gibco, Gaithersburg, MD) containing $20 \mathrm{ng} / \mathrm{ml}$ epidermal growth factor (Sigma, St. Louis, MO) and $10 \mathrm{ng} / \mathrm{ml}$ basic fibroblast growth factor (Sigma). Primary NS were cultured for 6 days in vitro, mechanically dissociated and passaged to form secondary NS at $6 \times 10^{3}$ cells per well in 12-well plates. To examine the effect of GCV on NS formation, NS were cultured: 1) in GCV- 
A

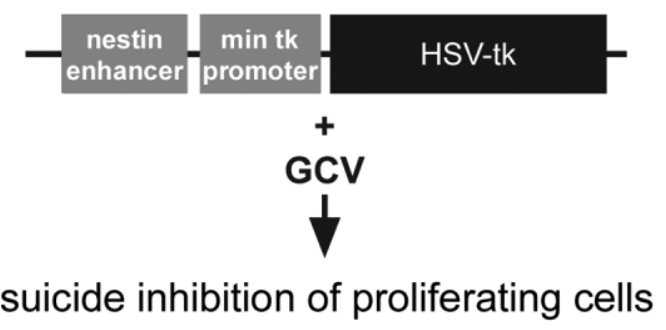

B

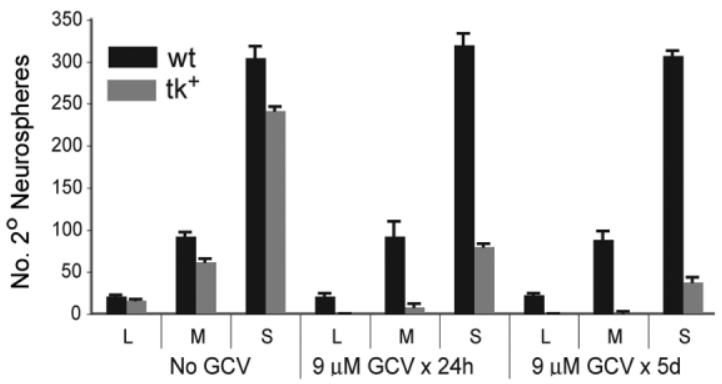

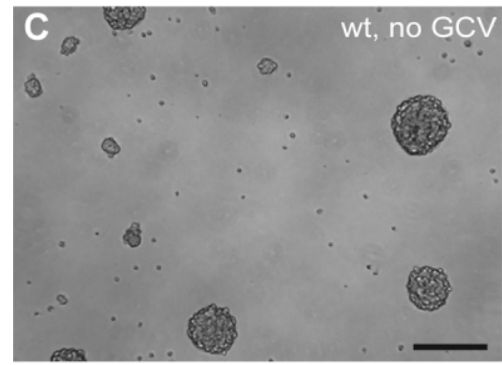
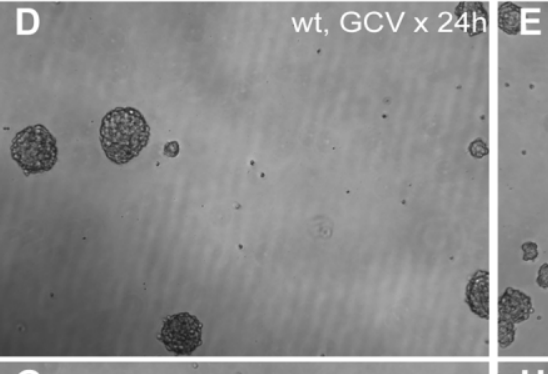

wt, GCV x 5c
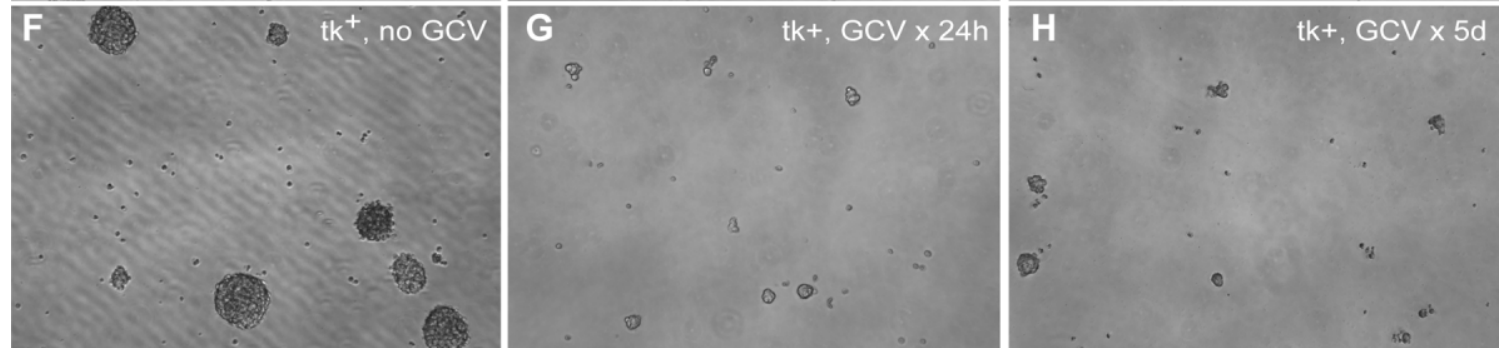

Figure 1.

Ganciclovir (GCV) administration suppresses formation of neurospheres (NS) derived from P40 nestin-tk mouse SVZ. A: This schematic of the nestin-tk construct shows that expression of the HSV-tk gene is under control of a nestin 2nd intronic enhancer element and minimal tk promoter. Administration of GCV to mice carrying this transgene results in death of dividing cells expressing HSV-tk. B: Culture of NS in GCV-containing media for 24 hours or 5 days results in decreased NS formation from nestin-tk ${ }^{+}\left(\mathrm{tk}^{+}\right)$mice relative to GCV-treated wild-type controls (wt; $P<0.001)$ or tk ${ }^{+}$NS cultures in basal media $(P<0.001)$ after 5 days in vitro. Black bars indicate number of large $(\mathrm{L})$, medium-sized (M), and small (S) NS derived from wt mice, whereas gray bars denote those derived from $\mathrm{tk}^{+}$mice. C-H: Representative phase contrast images of cultured NS after 5 day in vitro. NS from tk ${ }^{+}$mice cultured in GCV-containing media are markedly reduced $(\mathrm{G}, \mathrm{H})$ relative to those cultured in control media (F) or to cultures from wt controls grown in the presence or absence of GCV (C-E). Scale bar $=100 \mu \mathrm{m}$ in C (applies to C-H).

free medium as a control; 2) in medium containing $9 \mu \mathrm{M} \mathrm{GCV}$ for 24 hours and then in GCV-free medium for 4 days; or 3) in medium containing $9 \mu \mathrm{M}$ GCV for 5 days. At the end of the 5-day culture period, NS were measured and counted based on their diameters: small $(<0.1 \mathrm{~mm})$, medium $(0.1-0.8 \mathrm{~mm})$, and large $(>0.8 \mathrm{~mm})$.

\section{In vivo GCV administration}

For pilot studies, $100 \mathrm{mg} / \mathrm{kg}$ GCV (Cytovene, Roche, Indianapolis, IN) or $100 \mathrm{mg} / \mathrm{kg}$ elaidic acid esterified GCV (eGCV CP-4018, Clavis Pharma, Oslo, Norway; Balzarini et al., 1998) was administered daily via intraperitoneal (i.p.) injection. To improve penetration of the blood-brain barrier, eGCV was prepared in a liposomal solution according to the manufacturer's instructions. Briefly, a solution of eGCV $(25 \mathrm{mg} / \mathrm{ml})$ and phosphotidyl choline (100 mg/ml; Sigma) in ethanol was rapidly injected into water. The resulting suspension was then frozen $\left(-80^{\circ} \mathrm{C}\right)$ and lyophilized. The dried product was resuspended in a solution of glycerol and water $(22.4 \mathrm{mg} / \mathrm{ml})$ and briefly sonicated. In some experiments, osmotic minipump (Alzet, Cupertino, CA, model 2004) subcutaneous infusion was used as described previously (Garcia et al., 2004).
Due to the adverse systemic effects of i.p. or subcutaneous GCV and eGCV administration, for all subsequent experiments we administered GCV via ICV infusion at a rate of $0.25 \mu \mathrm{l} / \mathrm{hr}$ by using an osmotic minipump. Minipumps (Alzet, model 2004) were filled with $20 \mathrm{mM} \mathrm{GCV}$ or normal saline and primed for 36 hours at $37^{\circ} \mathrm{C}$. For implantation of the pump and cannula, mice were anesthetized with $130 \mathrm{mg} / \mathrm{kg}$ ketamine and 20 $\mathrm{mg} / \mathrm{kg}$ xylazine and fixed to a stereotaxic frame after loss of the paw withdrawal reflex. The osmotic pump was implanted subcutaneously over the scapulae, and fitted to an intraventricular cannula (Brain Infusion Kit 3, Alzet) implanted $0.21 \mathrm{~mm}$ anterior, $0.85 \mathrm{~mm}$ lateral, and $3.0 \mathrm{~mm}$ deep to Bregma. Following surgery, all mice were housed individually for the remainder of the experiment.

\section{Bromodeoxyuridine labeling and tissue processing}

Pulse bromodeoxyuridine (BrdU) labeling was used to identify mitotically active cells. BrdU $(100 \mathrm{mg} / \mathrm{kg})$ dissolved in phosphate-buffered saline (PBS; pH 7.4) was administered once by i.p. injection, and 2 hours later animals were killed by anesthetic overdose. Brains were perfusion-fixed with $0.9 \%$ $\mathrm{NaCl}$, followed by $4 \%$ paraformaldehyde (PFA) in phosphate 
buffer. In another set of experiments, BrdU was given once daily on days 10-12 after the start of the ICV infusion of GCV, and animals were killed at the end of the 28-day infusion. Brains were removed and postfixed overnight in $4 \%$ PFA, cryoprotected with $30 \%$ sucrose, embedded in freezing medium, frozen in dry ice and 2-methyl butane, and sectioned coronally at $50-\mu \mathrm{m}$ thickness.

\section{Immunohistochemistry}

For immunofluorescence labeling, sections were rinsed in Tris-buffered saline (TBS; pH 7.4) and incubated in blocking buffer for 1 hour prior to incubation with primary antibody. After three TBS washes, sections were incubated with Alexa Fluor 594- or 488-conjugated goat anti-mouse, -rat, or -rabbit IgG secondary antibody (1:400; Molecular Probes, Eugene, OR) at room temperature for 2 hours, washed three times with TBS, mounted on slides, and coverslipped with antifade medium (Pro-Long; Molecular Probes). For BrdU immunofluorescence, sections were incubated with $2 \mathrm{~N} \mathrm{HCl}$ at $37^{\circ} \mathrm{C}$ for 30 minutes to denature the DNA and then neutralized with $0.1 \mathrm{M}$ sodium borate ( $\mathrm{pH}$ 8.5) for 10 minutes. After TBS washes, sections were incubated with rat anti-BrdU (1:200; Accurate Chemical, Westbury, New York) at $4^{\circ} \mathrm{C}$ overnight and then processed as described above.

For diaminobenzidine (DAB) staining, sections were processed as follows: rinses with Tris buffer, deactivation of endogenous peroxidases with $1 \% \mathrm{H}_{2} \mathrm{O}_{2}$, rinses with Tris buffer containing Triton $\mathrm{X}-100 /$ bovine serum albumin (Tris-B), blocking with $10 \%$ normal goat serum in Tris-B for 1 hour, and then incubation with primary antibody at $4^{\circ} \mathrm{C}$ overnight (see below). After Tris buffer washes, sections were incubated with biotinylated horse anti-goat IgG (1:200; Jackson ImmunoResearch, West Grove, PA) and then avidin-biotin peroxidase (ABC) complex (Vector, Burlingame, CA). For color reaction, sections were incubated with stable DAB (Invitrogen), rinsed three times, mounted on slides, and coverslipped with Permount medium. For BrdU immunohistochemistry, sections were incubated with $2 \mathrm{~N} \mathrm{HCl}$ at $37^{\circ} \mathrm{C}$ for 30 minutes to denature the DNA, and then neutralized with $0.1 \mathrm{M}$ sodium borate (pH 8.5) for 10 minutes. After Tris washes, sections underwent peroxidase deactivation, rinsing, and blocking as above and incubation with mouse anti-BrdU (1:1,000, Roche) overnight at room temperature. After Tris washes, sections were incubated with biotinylated horse anti-mouse IgG (1:200; Jackson ImmunoResearch) and processed with $A B C$ complex and $D A B$ as above. Images were captured with a Leica DSM-IRB epifluorescence microscope and Spot-RT digital camera or, for double labeling, as a z-series of thin optical sections with a Zeiss LSM-510 confocal microscope. Digital images were imported into Adobe Photoshop v.6.0 (Adobe Systems, Mountain View, CA). Contrast and brightness were adjusted slightly to keep background intensity levels comparable among animals.

\section{Antibody characterization}

The monoclonal mouse anti-BrdU antibody (Roche, 1170376) was prepared against a BrdU-bovine serum albumin conjugate; it cross-reacts with iodouridine at $10 \%$ of the intensity of BrdU, but not fluorodeoxy-uridine, nor with any endogenous cellular components such as thymidine or uridine (manufacturer's information). Antibody was used at 1:1,000 titer, and staining was absent in tissue from mice not injected with BrdU. The monoclonal rat anti-Brdu antibody (Accurate
Chemical, OBT0030CX) was prepared against iodouridine conjugated to bovine serum albumin; it does not cross-react with thymidine (manufacturer's information; Vanderlaan and Thomas, 1985). Antibody was used at 1:200 titer, and staining was absent in tissue from mice not injected with BrdU.

The polyclonal goat anti-doublecortin (DCx) antibody (Santa Cruz Biotechnology, Santa Cruz, CA; sc-8066, C-18 clone) was prepared against the C-terminal of a synthetic DCx peptide corresponding to amino acids 385-402 at the C-terminus of human DCx (Swiss-Prot \#043911). The anti-DCx sc-8066 antiserum recognizes a $45-\mathrm{kDa}$ band by Western blot of human DCx-transfected 3T3-L1 whole cell lysate, does not react to lysate of untransfected cell lines, and is specific to DCx of mouse, rat, and human origin by Western blotting, immunoprecipitation, and immunohistochemistry; it does not crossreact with a related protein, KIAA0369 (manufacturer's information). The pattern of C-18 staining observed was consistent with that of previous studies that have examined birth-dating of DCx-immunoreactive neurons (Brown et al., 2003). Antibody was used at 1:2,000 titer.

The monoclonal mouse anti-GFAP antibody (Sigma; G3893, G-A-5 close) was prepared against GFAP purified from pig spinal cord; it recognizes GFAP-containing astrocytes and a 50-kDa protein on Western blots (manufacturer's information; Latov et al., 1979). Antibody was used at 1:500 titer.

The polyclonal rabbit anti-glucose transporter 1 (GLUT1) antibody (Chemicon, Temecula, CA; AB1340) was prepared against a synthetic peptide corresponding to amino acids at the C-terminus (C-ELFHPLGADSQV) of rat GLUT-1 (SwissProt \#P11166) coupled to keyhole limpet hemocyanin (KLH). It recognizes both the 55- and 45-kDa forms of GLUT1 on Western blot and does not react to colorectal cancer controls; it recognizes GLUT1 in human, mouse, and rat tissue (manufacturer's information; Smoak and Branch, 2000). Antibody was used at 1:800 titer.

The polyclonal rabbit anti-Ki67 antibody (Vector; VP-K451) was prepared against an isolated 20-mer peptide (NH2AGGDEKDIKAFMGTPVQKLD-COOH) corresponding to a 62-bp cDNA containing the Ki67 motif (Key et al., 1993a,b). This rabbit antiserum was shown to detect 345- and 395-kDa bands on Western blot of lysed IM- 9 cells, the same bands detected by the monoclonal Ki-67 antibody used to define the motif. The antibody was used at 1:500 titer and resulted in nuclear staining in proliferative brain regions consistent with that observed by other authors (Maslov et al., 2004).

The polyclonal goat anti-mini-chromosome maintenance protein 2 (MCM2) antibody (Santa Cruz Biotechnology; sc9839, N-19 clone) was prepared against a synthetic peptide corresponding to amino acids 1-30 at the N-terminus of human MCM2 (Swiss-Prot \#P49736, manufacturer's information). The anti-MCM2 sc-9839 antiserum recognizes a 127$\mathrm{kDa}$ band in nuclear extract of HeLa cells and is specific to MCM2 of rat, mouse, and human origin (manufacturer's information). The pattern of MCM-2 staining observed was consistent with that of previous studies examining double labeling of MCM-2 and BrdU (Maslov et al., 2004). Antibody was used at 1:200 titer.

The monoclonal mouse anti-NeuN antibody (Chemicon; MAB377, clone A60) was prepared against purified nuclei from mouse brain cells. The anti-NeuN antibody recognizes two to three bands in the $46-48-\mathrm{kDa}$ range and is specific to nuclei 
only of postmitotic neurons (manufacturer's information; Mullen et al., 1992). Antibody was used at 1:1,000 titer.

The monoclonal mouse anti-nestin antibody (Dr. Susan Hockfield, Developmental Studies Hybridoma Bank, University of lowa, Ames, IA; Rat-401) was prepared against homogenized E15 rat spinal cords. The anti-nestin antibody recognizes a single $200-\mathrm{kDa}$ band on Western blot; it stains neuroepithelial cells including neuronal progenitors (Hockfield and McKay, 1985). Antibody was used at 1:10 titer.

The monoclonocal rat anti-ED-1 antibody (Serotec, Bicester, UK; MCA1957) is raised against concavalin A acceptor protein from the P815 cell line (manufacturer's information). This antibody recognizes bands of 87-115 kDA corresponding to differentially glycosylated forms of ED-1 (da Silva and Gordon, 1999). In this study, the antibody was used at 1:200 titer. Staining revealed numerous small stellate cells, and staining of positive control tissue from known inflammatory states showed increased numbers of reactive cells.

\section{Cell counting}

Stereological estimates of cell number were performed with a computer-aided microscopy system (Visiopharm, Horsholm, Denmark) coupled to an Olympus BX51 microscope. Due to the low total number of labeled cells in each section, the entire region of interest in every 12th section through the DG contralateral to the site of ICV cannula implantation was examined at high power by using a $60 \times$, NA 1.35 oil immersion objective. In sections labeled for DCx, the region of interest comprised the entire granule cell layer of any section with a discernible border between the DGC layer and dentate hilus. In sections labeled for BrdU, the region of interest extended from the inner half of the DGC layer and penetrated two granule cell body widths into the dentate hilus. Blinded cell counts were then estimated by using an optical fractionator probe (West et al., 1991). The coefficent of variation in the set of sections from each mouse was calculated (Gundersen et al., 1999; Bermejo et al., 2003) and found to be less than $5 \%$.

\section{Tail suspension test}

Mice were implanted with an ICV cannula and received a continuous infusion of GCV for 28 days as previously described. Fourteen days after implantation, mice were injected (i.p.) once daily for 28 days with a single dose of imipramine (3, 10 , or $30 \mathrm{mg} / \mathrm{kg}$ ) or saline. Thirty minutes after the last imipramine dose, each mouse was evaluated in the tail suspension test. For this behavioral assay, tape was attached to the bottom half of each mouse's tail, and then it was secured to a metal pole suspended approximately 8 inches from a table surface. The mouse remained suspended and was videotaped for 6 minutes. The videotape was later scored for duration of immobility by one or two observers blind to the drug treatment and genotype; interscorer reliability was greater than $90 \%$. Immobility was defined as continuous periods of stillness, with an occasional small movement or isolated twitch allowed. Following the tail suspension test, brain tissue from each mouse was perfused and fixed as previously described. Imipramine was dissolved and diluted in saline, and all injections were administered in a volume of $1 \mathrm{ml} / 100 \mathrm{~g}$ of body weight.

\section{Statistics}

Comparisons among cell or NS counts in multiple treatment groups were performed by using one-way ANOVA, with post hoc t-tests and groupwise contrasts adjusted for multiple comparisons by Tukey's criterion. When appropriate, pairwise comparisons were made by using Student's t-test. All tests were two-tailed. Analyses of cell counts were performed by using SPSS 15 software (SPSS, Chicago, IL). Behavioral data were analyzed by one- or two-way ANOVA with Dunnett's post hoc test (Graphpad Prism [La Jolla, CA] software). If no interaction was observed, post hoc analyses were conducted on significant main effects. Data are presented as the mean plus 1 SEM, and $P<0.05$ was accepted as statistically significant.

\section{RESULTS \\ GCV suppresses nestin-tk ${ }^{+}$cell proliferation in vitro}

We first sought to determine whether the proliferation of postnatal neural stem cells could be suppressed in vitro by the administration of GCV in the presence of the nestin-tk transgene (Morshead et al., 2003). Neural stem cells from the postnatal rodent forebrain expand in vitro when cultured as floating NS (Gritti et al., 1996; Reynolds and Weiss, 1992; Gritti et al., 1996; Tropepe et al., 1999; Seaberg and van der Kooy, 2002). We therefore derived NS cultures from the SVZ of P40 nestin-tk ${ }^{+}$mice and wild-type littermates, cultured them for 5 days after first passage in the presence or absence of GCV, and analyzed the NS based on their numbers and sizes (small, $<0.1 \mathrm{~mm}$; medium, 0.1-0.8 mm; and large, >0.8 mm).

Cultures derived from wild-type mice produced similar numbers of NS regardless of whether they were grown in GCV-free media or in media containing $9 \mu \mathrm{M}$ GCV for 24 hours or for the entire 5-day culture period (Fig. 1B-E). Cultures from nestin-tk ${ }^{+}$mice, however, produced significantly fewer small and medium-sized secondary NS when exposed to GCV for either 24 hours or 5 days than when grown in basal media, or when compared with wild-type derived cultures grown with GCV $(\mathrm{F}(17,54)=355.7, P<0.001$; Fig. 1B-H). The number of large nestin-tk ${ }^{+}$NS was also reduced in the presence of GCV compared with wild-type cultures treated with GCV and nestin- $\mathrm{tk}^{+}$cultures in basal media, but the difference was not significant. In addition, nestin-tk ${ }^{+}$cultures in basal media produced slightly, but significantly, fewer NS than wild-type derived cultures under the same conditions $(P<0.001$; Fig. 1B,C,F).

These findings indicate that in vitro treatment with GCV in the presence of the nestin-tk transgene suppresses NS formation from postnatal SVZ-derived neural progenitors. This effect was observed after 5 days of continuous GCV exposure or after 24 hours of GCV exposure followed by 4 days in basal media, suggesting that GCV administration results in a rapid, prolonged ablation of a large portion of the stem cell population in vitro. As expected, GCV did not influence the proliferation of SVZ stem cells derived from wild-type mice. We did note, however, that NS formation was slightly diminished in cultures derived from nestin-tk ${ }^{+}$mice versus wild-type even in the absence of GCV (Fig. 1B, left side), raising the possibility that either the transgene product or site of insertion has a deleterious effect on stem cell proliferation. 
In the absence of GCV treatment, the nestin-tk transgene does not impair basal cell proliferation and adult neurogenesis in vivo

Before conducting experiments evaluating the effect of GCV on adult neurogenesis in vivo, we examined whether the presence of the nestin-tk transgene alone altered forebrain SVZ and dentate SGZ cytogenesis. Three-month-old mice received a single BrdU injection (100 $\mathrm{mg} / \mathrm{kg}$, i.p.), and the pattern of BrdU immunoreactivity was examined 2 hours later. The forebrain SVZ of both untreated wild-type and untreated nestin-tk ${ }^{+}$mice contained a similar pattern of large numbers of BrdU-immunoreactive nuclei (Fig. 2A,B). The dentate SGZ contained clusters of BrdU-labeled cells (Fig. 2E,F), and no difference was found in the number of BrdU-immunoreactive cells in the SGZ of nestin-tk ${ }^{+}$mice and wild-type littermates ( $P>0.5$, Fig. 2G; $n=6$ /group). Although pulse BrdU labeling reveals the number of $S$-phase cells during a brief time, we sought a more integrated view of neurogenesis by examining immunoreactivity for DCx, a microtubule binding protein expressed by immature neurons for several weeks after birth (Brown et al., 2003; Couillard-Despres et al., 2005). Both wildtype and nestin-tk ${ }^{+}$mice displayed abundant DCx immunoreactivity in the SVZ and in the DGC layer (Fig. 2C,D,H,I). There was no significant difference in the number of $\mathrm{DCx}^{+}$cells in the DG of wild-type and nestin-tk ${ }^{+}$mice (Fig. $2 \mathrm{~J} ; P>0.5, \mathrm{n}=$ $6 /$ group). Thus, despite the small disparity in proliferative potential among nestin-tk ${ }^{+}$and wild-type NS observed in vitro, the presence of the nestin-tk transgene does not reduce the rates of cell division or neurogenesis in vivo in the main neurogenic regions of the adult brain. Additional studies using other nestin-tk mouse lines would be helpful to establish the reason for the differences we found in vitro.

\section{Systemic GCV administration in adult nestin-tk ${ }^{+}$} mice suppresses SVZ and SGZ cell proliferation

To determine whether GCV treatment would effectively reduce neurogenesis in nestin- $\mathrm{tk}^{+}$mice in vivo, we first examined the effect of systemically administered GCV on cytogenesis in the SVZ and SGZ. Adult mice received a liposomal solution of eGCV for 14 days ( $100 \mathrm{mg} / \mathrm{kg} / \mathrm{d}$, i.p.). On the day after eGCV treatment ended, a single pulse of BrdU (100 $\mathrm{mg} / \mathrm{kg}$ ) was administered, and BrdU immunoreactivity was examined 2 hours later. Although the SVZ and SGZ of wildtype animals treated with eGCV showed robust BrdU labeling commensurate with untreated controls (Fig. 2K,M), BrdU labeling was dramatically reduced in nestin-tk ${ }^{+}$mice after eGCV treatment (Fig. 2L,N). Similarly, nestin immunoreactivity in the SVZ was virtually absent after eGCV administration in nestin-tk ${ }^{+}$mice (Fig. 2O,P). Comparable findings were seen after GCV was administered subcutaneously (data not shown). These results indicate the potential of systemic GCV administration in nestin-tk ${ }^{+}$mice to achieve cytostasis in neurogenic regions, and indeed to deplete the population of nestinexpressing progenitor cells.

Peripheral administration of either GCV or eGCV in a concentration and duration sufficient to suppress cell division in the SVZ and SGZ, however, also resulted in significant systemic toxicity. Nestin-tk ${ }^{+}$mice lost up to $30 \%$ of their body weight and suffered $100 \%$ mortality by 16 days after the initiation of GCV or eGCV administration. The mortality that accompanied GCV treatment may relate to ablation of nestin- expressing pancreatic cells, as we found that the weight of the pancreatic mass in nestin-tk ${ }^{+}$mice was reduced by over $50 \%$ after GCV treatment compared with GCV-treated wild-type controls (data not shown). Despite multiple experiments varying GCV and eGCV concentrations, administration rate, and peripheral administration route, including subcutaneous osmotic minipump infusion (Garcia et al., 2004), we were unable to achieve effective concentrations of GCV in the brain without causing systemic toxicity.

\section{ICV infusion of GCV ablates proliferation and neurogenesis in the $\mathrm{SVZ}$ and SGZ}

We sought to take advantage of the limited capacity of GCV to cross the blood-brain barrier (Bodor and Buchwald, 1999) and circumvent systemic effects by infusing GCV directly into the lateral ventricle. Mice were implanted with an ICV cannula and received a continuous infusion of $2 \mathrm{mM} \mathrm{GCV}$ or saline vehicle for 28 days via osmotic minipump $\left(n=7 \mathrm{tk}^{+}+\mathrm{GCV}\right.$, $5 \mathrm{tk}^{+}+$vehicle, 4 wild-type + vehicle). The 28-day infusion duration was chosen to eliminate an extensive cohort of adultborn neurons over the time that they would begin to integrate, 2-4 weeks (reviewed in Ming and Song, 2005), in preparation for later behavioral studies. Utilizing this administration route, we did not observe any differences in the overt behavior of wild-type or nestin-tk ${ }^{+}$mice, and there was no mortality following GCV administration. In addition, the weights of the mice did not differ after GCV infusion (wild-type: mean $31.1 \pm$ $1.6 \mathrm{~g}$; nestin-tk ${ }^{+}$: mean $29.9 \pm 1.2 \mathrm{~g}, P>0.5, \mathrm{n}=12$ /group). Following 28 days of ICV infusion, we examined proliferation and neurogenesis in the SVZ-olfactory bulb pathway and hippocampal DG. The number of mitotically active cells in the SVZ labeled by the cell-cycle protein Mcm2 (Maslov et al., 2004) was greatly reduced in nestin-tk ${ }^{+}$mice after GCV administration (Fig. $3 \mathrm{C}$ ) compared with vehicle-treated transgenic and GCV-treated wild-type controls (Fig. 3A,B). We observed the same result by using Ki67 labeling as a marker of cell proliferation (data not shown). This reduction in precursor proliferation was further reflected in the complete loss of DCx-immunoreactive neuroblasts in the SVZ (Fig. 3D-F) and olfactory bulb (Fig. 3Gb-l) of nestin-tk ${ }^{+}$mice following GCV treatment.

The suppression of neurogenesis was also effective in the DG. After 28 days of GCV treatment, the SGZ of nestin-tk ${ }^{+}$ mice was nearly completely devoid of proliferating cells labeled by Mcm2 (Fig. 4A-C) or Ki67 (data not shown). The

Figure 2.

A-J: Immunolabeling for bromodeoxyuridine (BrdU) (A,B,E,F) and doublecortin (DCX) $(\mathrm{C}, \mathrm{D}, \mathrm{H}, \mathrm{I})$ shows robust cell proliferation and production of immature neurons in both the subventricular zone (SVZ; A-D) and dentate gyrus (DG; E,F,H,I) of untreated, 3-month-old wildtype (wt) and nestin-tk ${ }^{+}\left(\mathrm{tk}^{+}\right)$mice. No significant difference in stereological estimates of the number of $\operatorname{BrdU}(G)$ or DCx (J) immunolabeled cells in the DG was observed between untreated wt or $\mathrm{tk}^{+}$mice. K-P: Intraperitoneal injection of eGCV for 14 days dramatically reduces proliferation, as indicated by labeling for pulse-administered BrdU, in the SVZ (L) and SGZ (N) of $\mathrm{tk}^{+}$mice relative to wt controls $(\mathrm{K}, \mathrm{M})$. BrdU was injected 2 hours prior to perfusion. The population of nestin-positive cells in the SVZ is also depleted in $\mathrm{tk}^{+}$mice $(P)$ compared with controls $(\mathrm{O})$. LV, lateral ventricle; STM, striatum; cc, corpus callosum; GCL, granule cell layer; $\mathrm{H}$, hilus; $\mathrm{ML}$, molecular layer. Scale bar $=200 \mu \mathrm{M}$ in A (applies to A-D), E (applies to E,F,H,I), K (applies to $\mathrm{K}, \mathrm{L}$ ), and $100 \mu \mathrm{m}$ in $\mathrm{M}$ (applies to $\mathrm{M}, \mathrm{N}$ ) and $\mathrm{O}$ (applies to O,P). 


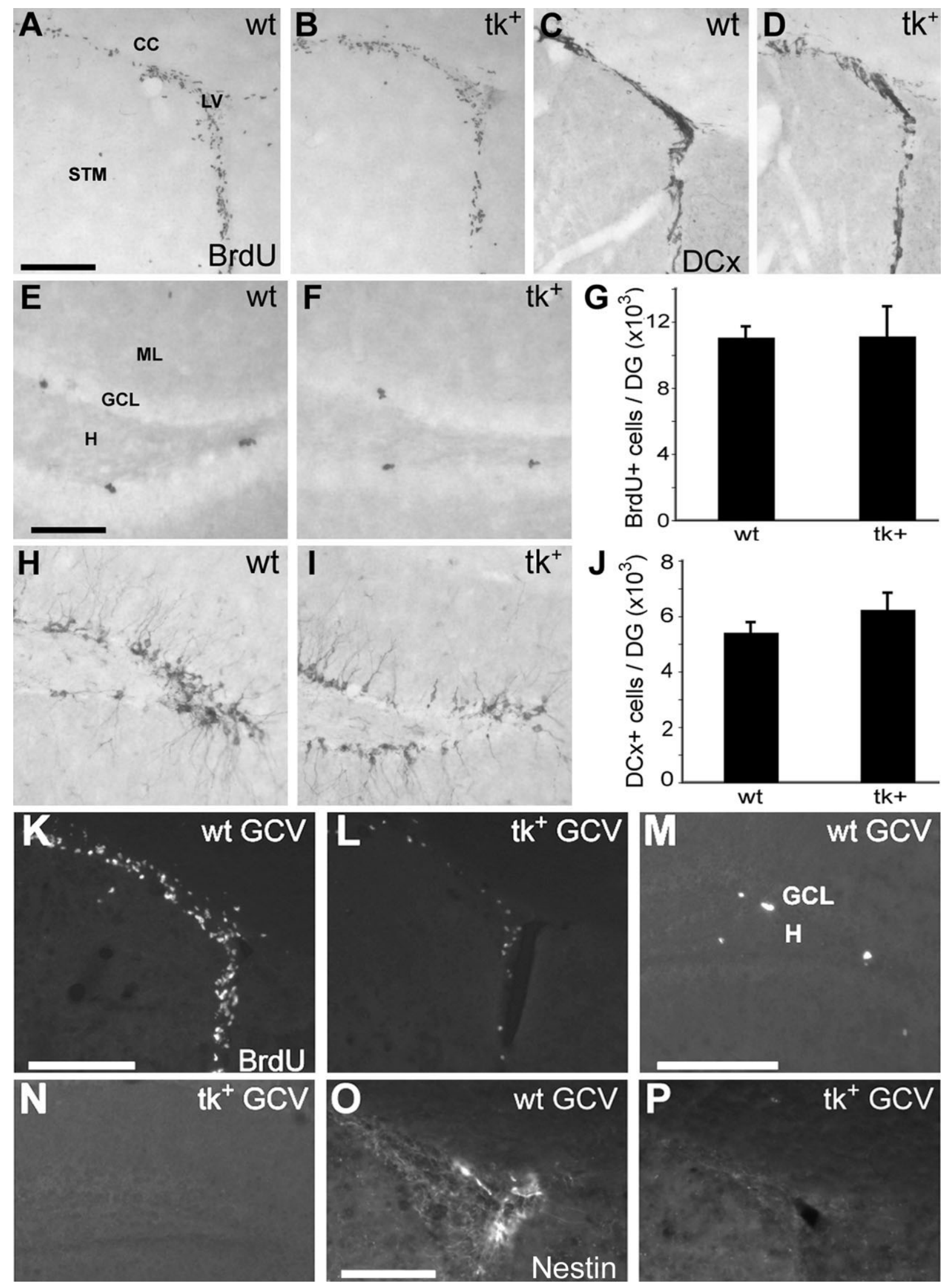



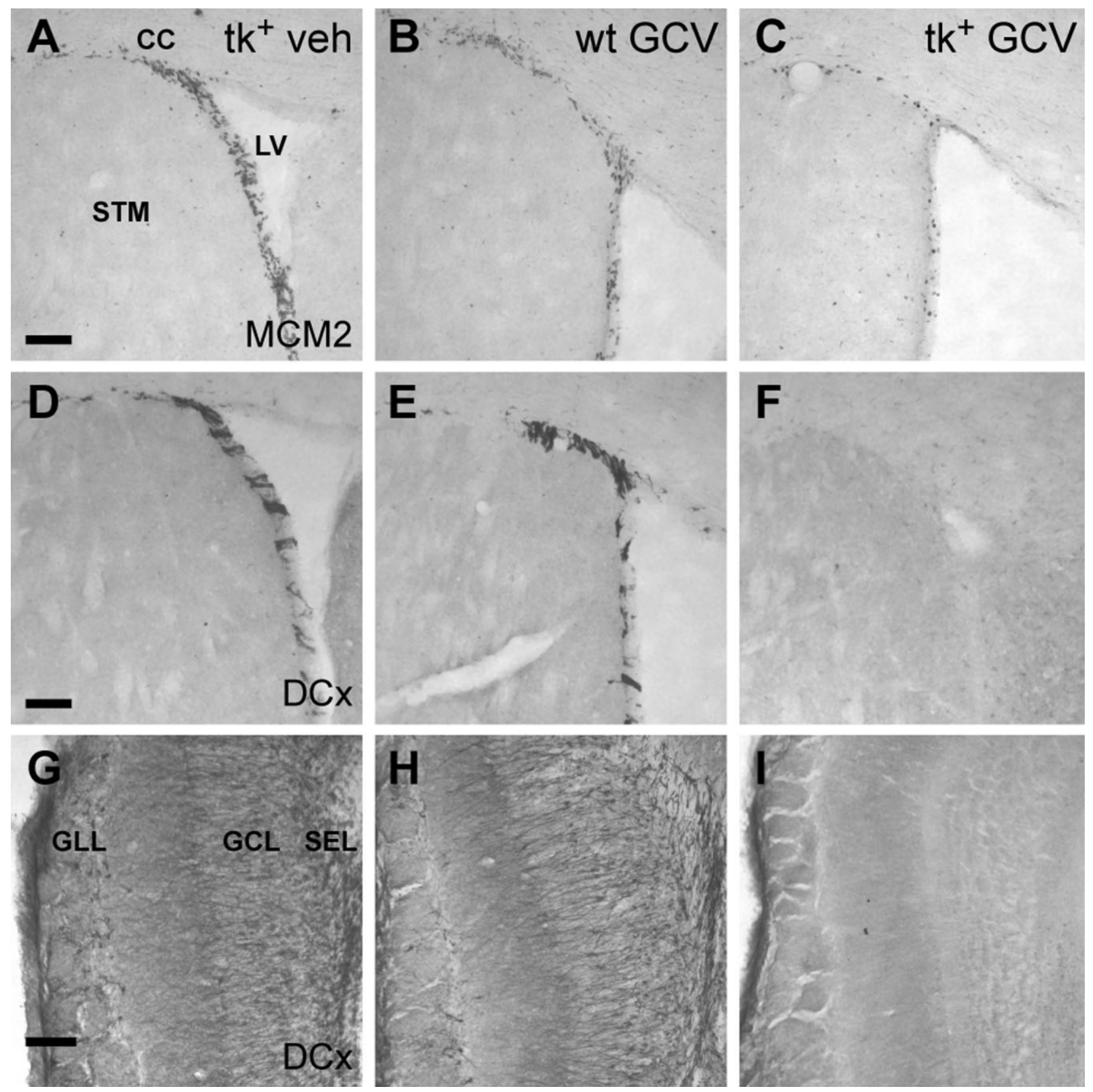

Figure 3.

ICV infusion of ganciclovir (GCV) for 28 days dramatically reduces both cell proliferation and the number of immature neurons in the SVZ-olfactory bulb pathway of nestin-tk ${ }^{+}\left(\mathrm{tk}^{+}\right)$mice. A-C: Whereas the SVZ of both vehicle-treated tk ${ }^{+}$(A) and GCV-treated wild-type (wt; B) mice contains numerous mitotically active cells labeled by MCM2, little labeling is observed in the SVZ of tk ${ }^{+}$mice treated with 28 days of GCV (C). D-F: Immature neurons labeled by double cortin (DCx) are absent from the SVZ of tk ${ }^{+}$mice treated with GCV (F), but are not depleted in vehicle (veh)-treated (D) or GCV-treated (E) controls. G-I: The ultimate destination of neurons generated in the SVZ, the olfactory bulb, also demonstrates reduced DCx labeling of immature neurons in $\mathrm{tk}^{+}$mice treated with GCV (I) relative to controls (G,H). LV, lateral ventricle; STM, striatum; cc, corpus callosum; SEL, olfactory subependymal layer; GCL, granule cell layer; GLL, glomerular layer. Scale bar $=100 \mu \mathrm{m}$ in A (applies to A-C), D (applies to D-F), and G (applies to G-I).

number of immature neurons in the DGC layer labeled by DCx was also reduced by $95 \%(\mathrm{~F}(2,14)=6.88, P<0.01)$ in nestin$\mathrm{tk}^{+}$mice receiving GCV, whereas there was no difference in the number of DCx-labeled cells among nestin-tk ${ }^{+}$mice treated with vehicle and GCV-treated wild-type mice $(P>$ 0.05; Fig. 4D-G). To confirm the reduction in neurogenesis, we administered BrdU during days 10-12 of the GCV infusion and perfused animals at the end of the 28-day infusion. Analysis of 

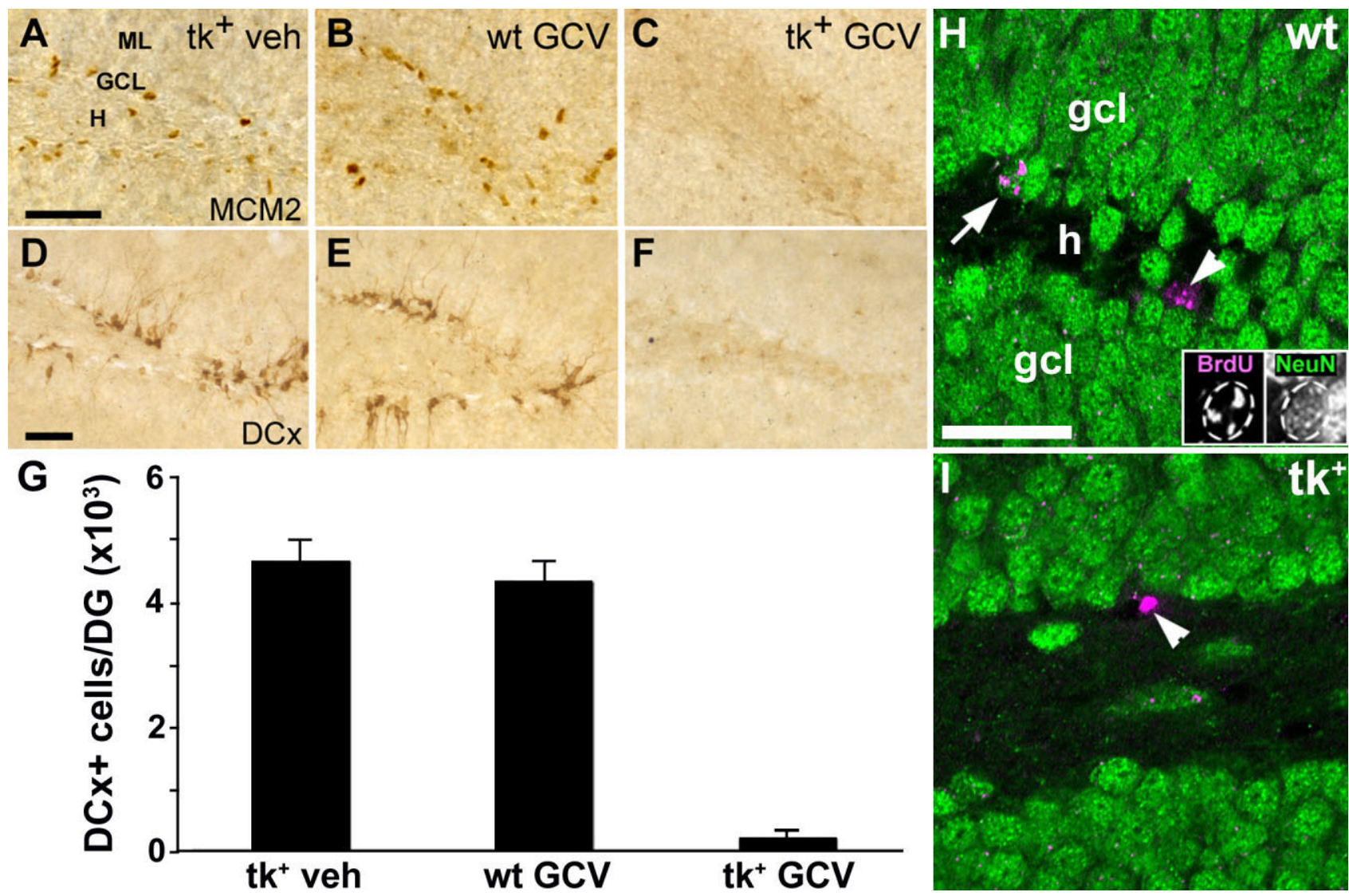

Figure 4.

ICV infusion of ganciclovir (GCV) for 28 days dramatically reduces both cell proliferation and the number of immature neurons in the DG of nestin-tk ${ }^{+}\left(\mathrm{tk}^{+}\right)$mice. A-C: Whereas the SGZ of both vehicle-treated nestin-tk ${ }^{+}\left(\mathrm{tk}^{+}\right)$and GCV-treated wild-type (wt) mice contains numerous mitotically active cells expressing Mcm2 (A, B), few cells label for this cell cycle marker in the SGZ of tk ${ }^{+}$mice treated with 28 days of GCV (C). D-F: Immature neurons immunolabeled for double cortin (DCx) are absent from the DG of $\mathrm{tk}^{+}$mice treated with GCV (F), but are not depleted in vehicle-treated $\mathrm{k}^{+}(\mathrm{D})$ or GCV-treated wt $(\mathrm{E})$ controls. G: Quantitative analysis shows that DCx-immunoreactive cell numbers are $95 \%$ lower in GCV-treated tk ${ }^{+}$mice than in either control group $(P<0.01)$. $\mathbf{H}$,I: Representative confocal images of sections double-labeled for BrdU (magenta) and NeuN (green) show both double-labeled (arrow) and single-labeled (arrowhead) cells in the granule cell layer (GCL) of a GCV-treated wt control $(\mathrm{H})$, but only a cell single-labeled for BrdU in a tk ${ }^{+}$animal after 28 days of GCV treatment (arrowhead in I). Nonmerged images of the double-labeled cell (arrow) are shown as insets in $\mathrm{H}$. BrdU was given 16-18 days earlier (days 10-12 of GCV infusion). D, dentate gyrus; $\mathrm{H}$ and h, hilus; GCL and gcl, granule cell layer; ML, molecular layer. Scale bar $=50 \mu \mathrm{m}$ in A (applies to A-C), D (applies to D-F), and H (applies to H,I).

double labeling for BrdU and the mature neuronal marker NeuN by confocal microscopy showed that about $50 \%$ of BrdU-labeled cells co-expressed NeuN in wild-type controls treated with GCV, whereas no double labeling was found in GCV-treated, nestin-tk ${ }^{+}$animals (Fig. 4H,l; n = 3 mice/group). Furthermore, we did not observe any differences in GFAP and Glut1 immunoreactivity in the DG among nestin-tk ${ }^{+}$and wildtype mice treated with GCV, suggesting that the loss of mitotically active precursors does not elicit frank gliosis or vascular changes in the hippocampus (data not shown; Latov et al., 1979; Smoak and Branch, 2000). Further supporting a lack of inflammatory response in nestin-tk ${ }^{+}$mice treated with GCV, we found no increase in activated microglia by ED-1 immunostaining except along the cannula track, and the degree was similar between treatment and control groups.

These results demonstrate that ICV administration of GCV for 28 days leads to a dramatic reduction in cellular proliferation in both neurogenic regions of the adult mouse brain.
Moreover, this loss of proliferation leads to a nearly complete depletion of DCx-immunoreactive cells in both the olfactory bulb and DG. Because immature neurons express DCx for several weeks following their birth, their absence suggests that neurogenesis is suppressed rapidly and that the suppression is maintained for the duration of GCV administration (Brown et al., 2003). Depletion of adult-born neurons was further suggested by the absence of double labeling for BrdU and the mature neuronal marker NeuN.

\section{Proliferation and neurogenesis recover slowly after cessation of GCV administration}

The nearly complete ablation of neurogenesis following 28 days of GCV administration suggests that the pool of nestinexpressing progenitor cells may be gradually depleted as they enter the cell cycle. To study the capacity of the remaining SVZ and SGZ progenitors to restore newborn neurons to the olfactory bulb and DG after a period of suppression, we ter- 


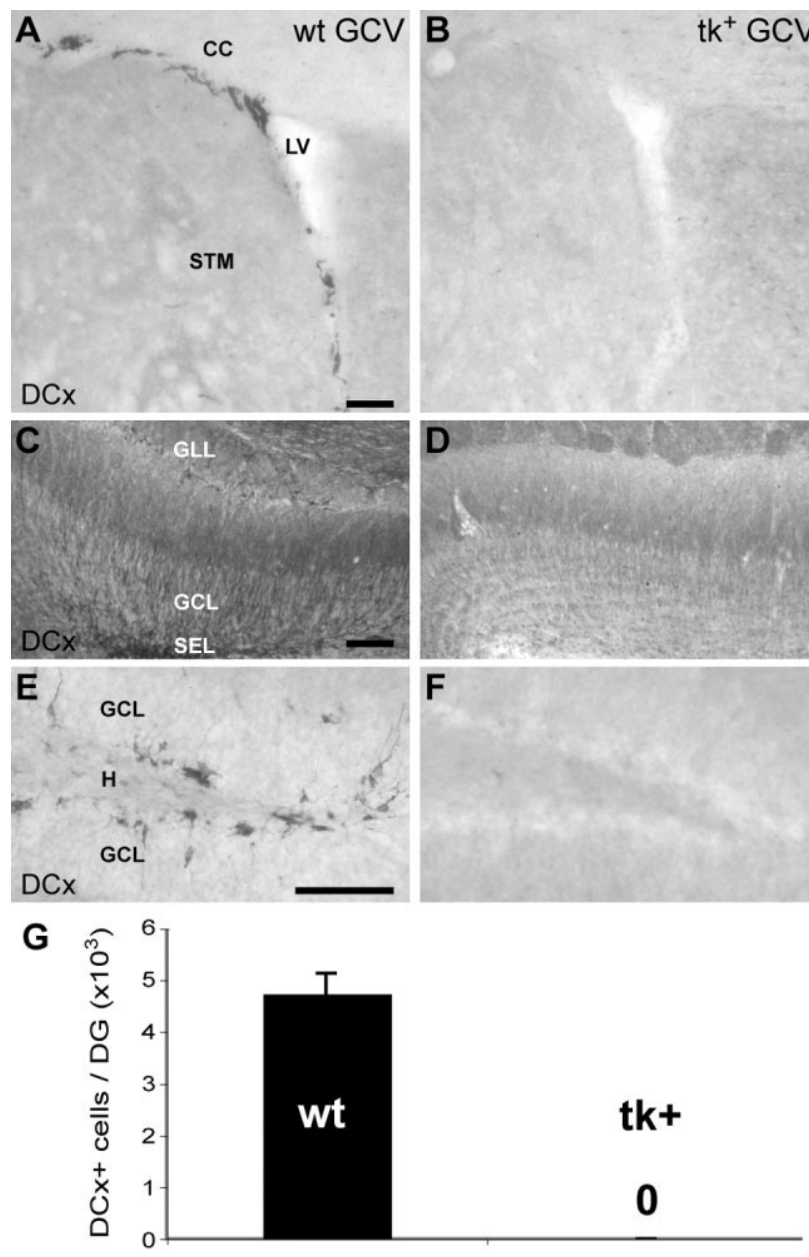

Figure 5

Two weeks after discontinuation of a 28-day ganciclovir (GCV) infusion, immature neurons remain absent from the SVZ, olfactory bulb, and DG. A-D: The SVZ (B) and olfactory bulb (D) of a nestin-tk ${ }^{+}\left(\mathrm{tk}^{+}\right)$ mouse does not contain any doublecortin (DCx)-immunoreactive neuroblasts after a 2-week recovery period, whereas a GCV-treated control (wt) shows many labeled cells (A,C). E,F: No immature neurons are observed in the DG of a tk ${ }^{+}$mouse immunolabeled for DCx $(F)$ after a 2-week recovery period, compared with the robust labeling evident in the GCV-treated wt (E). G: Stereological cell counts of DCximmunoreactive cells show failure of the $D G$ to reconstitute neurogenesis following 2 weeks of recovery from a 28-day GCV infusion in $\mathrm{tk}^{+}$ mice versus wt controls $(P<0.001)$. DG, dentate gyrus; LV, lateral ventricle; STM, striatum; CC, corpus callosum; SEZ, GCL, olfactory or dentate granule cell layer; SEL, olfactory subependymal layer; GLL, glomerular layer; $\mathrm{H}$, dentate hilus. Scale bar $=100 \mu \mathrm{m}$ in A (applies to $A, B$ ), C (applies to C,D), and E (applies to E,F).

minated GCV administration after 28 days and examined mice following a 2-week or 6-week recovery period. Following 2 weeks of recovery after GCV treatment, no DCx-labeled neuroblasts or interneurons were observed in either the SVZ or OB, respectively, in nestin-tk ${ }^{+}$mice (Fig. 5A-D). Similarly, the DG was devoid of DCx-immunoreactive cells in nestin-tk ${ }^{+}$ mice compared with wild-type animals (Fig. 5E-G; $P<0.001$; $n=3$ /group).

The lack of DCx-labeled cells in either the SVZ or DG after 2 weeks of recovery could reflect complete ablation of the neural progenitor population, or could result from the relative quiescence of progenitors that survive the death of dividing cells during GCV administration. We therefore examined the SVZ-olfactory bulb pathway and DG 6 weeks after the cessation of GCV to allow for additional expansion and differentiation of the progenitor population. In the SVZ, some cells expressing Mcm2 (Fig. 6A,B) and Ki67 (data not shown) appeared in both nestin-tk ${ }^{+}$and wild-type control mice following 6 weeks of recovery from GCV treatment. In addition, DCX-immunoreactive neuroblasts were present in the SVZ and olfactory bulb in nestin-tk ${ }^{+}$mice, albeit at reduced numbers compared with wild-type controls (Fig. 6C-F).

Proliferating cells and immature neurons also began to repopulate the DG after 6 weeks of recovery (Fig. 7). However, unlike the recovery of neurogenesis in the SVZ, which was present bilaterally, nascent recovery of neurogenesis was only evident unilaterally in the SGZ. Although Mcm2- and Ki67labeled cells were present bilaterally in wild-type controls after 28 days of ICV GCV treatment and 6 weeks of recovery (Fig. 7A; Ki67, data not shown), they were only evident in nestin-tk ${ }^{+}$mice in the SGZ contralateral to the side of GCV infusion (Fig. 7B; Ki67, data not shown). Similarly, no DCXlabeled cells were present ipsilateral to the infused lateral ventricle, whereas sparse labeling was observed contralaterally (Fig. 7D,E). Quantification of DCx-immunoreactive cells revealed a significant decrease ipsilaterally (Fig. $7 \mathrm{E} ; \mathrm{F}(2,10)=$ 8.34, $P<0.01 ; \mathrm{n}=7$ /group) and a trend toward persistent reduction contralaterally $(P<0.125)$ compared with GCVtreated, wild-type controls. Nestin and GFAP immunoreactivity persisted in radial glia-like cells in the DG of $\mathrm{tk}^{+}$mice after the 28-day GCV infusion (data not shown), suggesting that type 1 stem-like cells were not entirely eliminated. Thus, the repopulation dynamics after 28 days of GCV administration indicate that some progenitor cells survive throughout the period of GCV infusion and are able to reconstitute neurogenesis, although neurogenesis recurs bilaterally in the SVZ but only in the DG contralateral to the GCV infusion.

\section{Ablation of proliferation and neurogenesis does not alter the antidepressant-like effects of imipramine in vivo}

Reductions in forebrain neurogenesis were evaluated in an animal model used to identify antidepressant-like activity, the mouse tail suspension test. In nonimplanted, wild-type FVB mice, chronic imipramine administration dose-dependently decreased immobility in the tail suspension test $(F(3,22)=$ 9.67, $P=0.0004$; Fig. 8A). Significant decreases were observed at $10-\mathrm{mg} / \mathrm{kg}(P<0.05)$ and $30-\mathrm{mg} / \mathrm{kg}(P<0.001)$ doses compared with saline treatment. Chronic imipramine administration also decreased immobility in single-housed, GCV-treated wild-type littermate and nestin-tk ${ }^{+}$mice (main effect for imipramine: $\mathrm{F}(3,62)=13.41, P<0.0001$; Fig 8B); however, the nestin-tk transgene did not significantly alter the effects of imipramine (interaction: $\mathrm{F}(3,62)=0.15, P=0.93$; main effect for nestin-tk transgene: $\mathrm{F}(1,62)=0.014, P=0.91$ ). Significant decreases in immobility were observed at 10 $\mathrm{mg} / \mathrm{kg}(P<0.05)$ and $30 \mathrm{mg} / \mathrm{kg}(P<0.001)$ compared with saline independent of the transgene. As expected, GCV treatment led to a nearly complete cessation of neurogenesis only in transgenic mice (Fig. 8C,D). GCV treatment did not markedly attenuate DCx immunoreactivity in two of seven nestin$\mathrm{tk}^{+}$mice in the $30-\mathrm{mg} / \mathrm{kg}$ imipramine dose group, but exclu- 

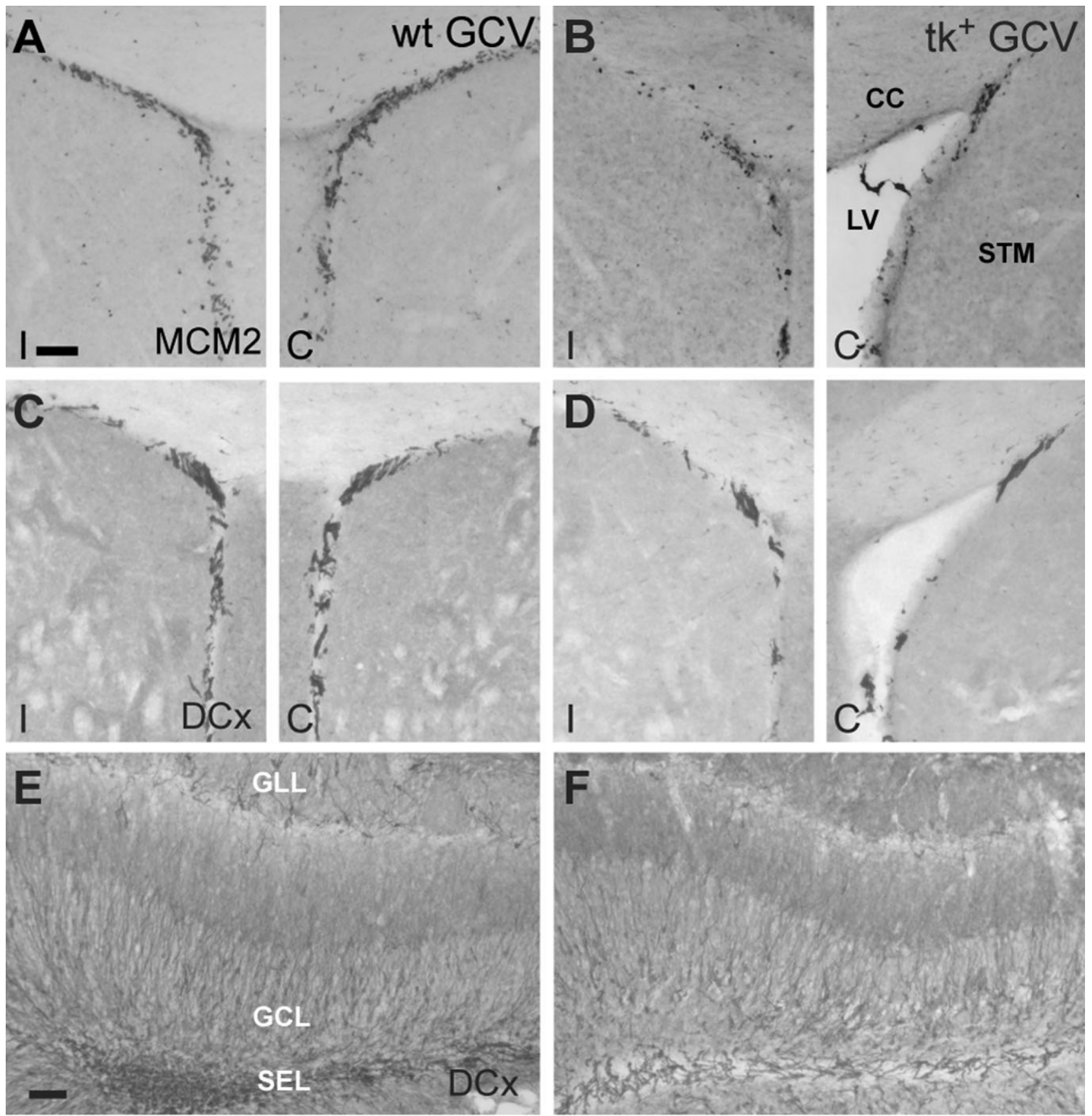

Figure 6.

Six weeks after discontinuation of a 28-day ganciclovir (GCV) infusion, both cell proliferation and neurogenesis recover in the SVZ. A,B: After 6 weeks of recovery, the SVZ of nestin- $\mathrm{tk}^{+}\left(\mathrm{tk}^{+}\right)$mice treated with GCV for 28 days contains proliferating cells labeled by Mcm2 (B). Mcm2-labeled cells are found both ipsilateral (I, lower left) and contralateral (C, lower left) to the implantation site of the ICV cannula, although they are less numerous than observed in wild type (wt) controls after the same GCV treatment and recovery period (A). C,D: Neurogenesis also returns bilaterally in the SVZ after 6 weeks of recovery. Immature neurons immunolabeled for doublecortin (DCx) appear in the SVZ of both tk ${ }^{+}$ mice (D) and wt controls (C), although they are less numerous in the tk ${ }^{+}$animal (D). E,F: Recovery of neurogenesis is sufficiently established after 6 weeks that immature neurons are evident in the olfactory bulb of a $\mathrm{tk}^{+}$mouse (F); however, the numbers have not returned to control levels (E). LV, lateral ventricle; STM, striatum; CC, corpus callosum; SEL, olfactory subependymal layer; GCL, granule cell layer; GLL, glomerular layer. Scale bar $=100 \mu \mathrm{m}$ in A (applies to A-D) and E (applies to E,F).

sion of these two mice did not change results of the analysis (interaction: $\mathrm{F}(3,60)=0.03, P=0.99$; main effect for nestin-tk transgene: $F(1,60)=0.02, P=0.89$; main effect for imipra- mine: $F(3,60)=14.22, P<0.000 I)$. Similar behavioral effects were observed between nonimplanted FVB mice and GCVtreated wild-type and nestin-tk ${ }^{+}$mice, demonstrating that 

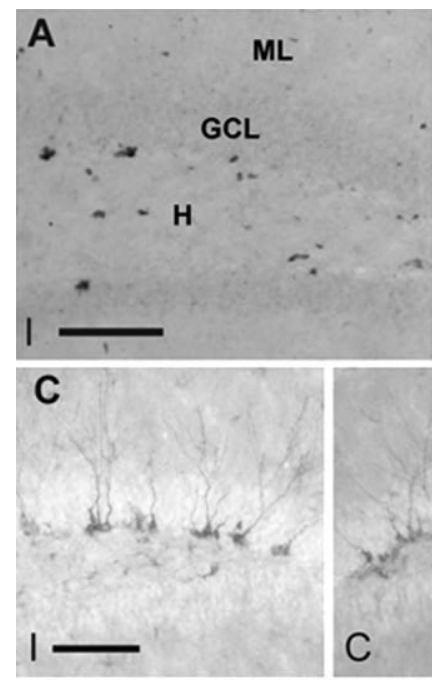
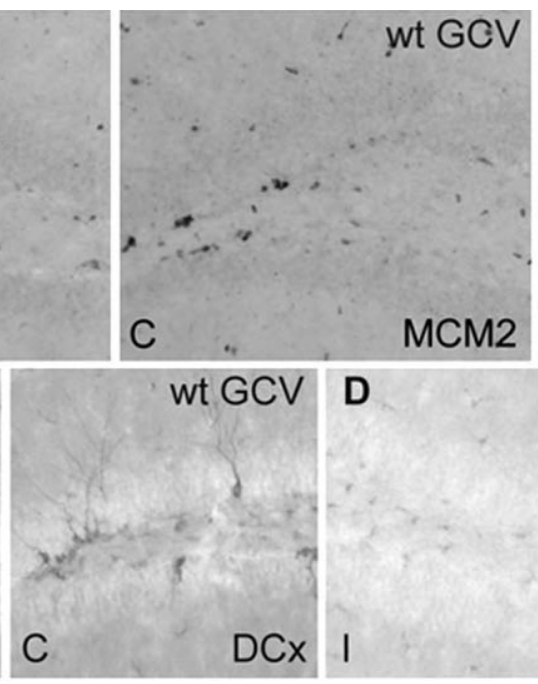

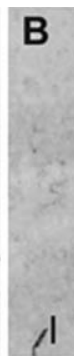

B
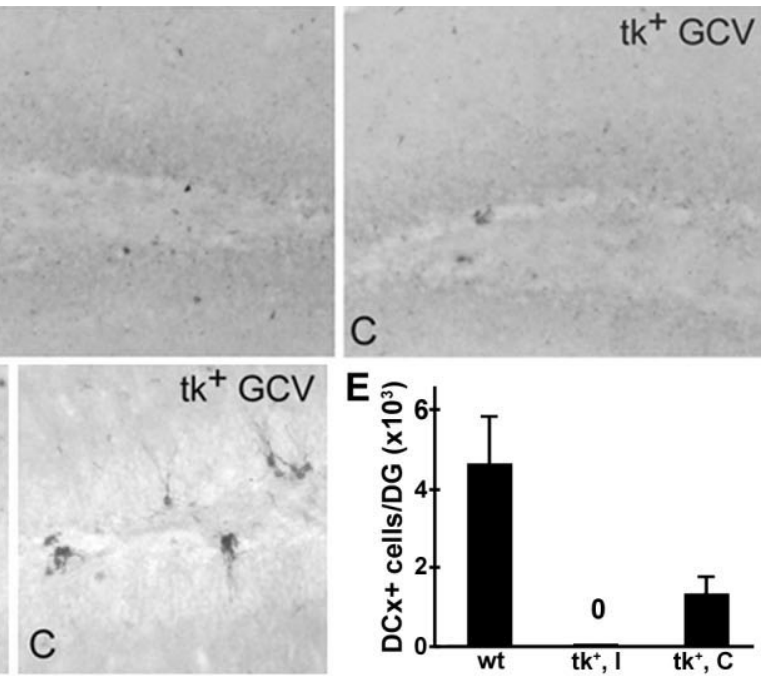

Figure 7.

Six weeks after discontinuation of a 28-day ganciclovir (GCV) infusion, both proliferation and neurogenesis recover in the DG contralateral to the site of GCV infusion. A,B: Mcm2-immunoreactive, proliferating cells are found only contralateral (C, lower left) to the side of GCV infusion in the DG of a nestin-tk ${ }^{+}\left(\mathrm{tk}^{+}\right)$animal (B) as opposed to bilaterally in a wild-type (wt) control (A). C-E: Immature neurons immunolabeled for doublecortin (DCX) are present contralateral (C, lower left) but not ipsilateral (l, lower left) to the side of GCV infusion in this tk ${ }^{+}$mouse (D), although more immature neurons are apparent in the wt control (C,E). GCL, granule cell layer; H, hilus; ML, molecular layer. Scale bar $=50 \mu \mathrm{m}$ in A (applies to A,B); $100 \mu \mathrm{m}$ in C (applies to C,D).

surgical implantation and ICV infusion of GCV did not have any significant behavioral consequences for baseline immobility behavior or on the effects of imipramine. These data therefore indicate that adult neurogenesis is not required for antidepressant-like responses of mice in the tail suspension model of antidepressant efficacy.

\section{DISCUSSION}

Our results indicate that administration of GCV to mice expressing the nestin-tk transgene effectively ablates adult neurogenesis in both the SVZ/OB and SGZ/DG pathways. Infusion of GCV into the lateral ventricle for 28 days led to suppression of cell proliferation in both the SVZ and SGZ, and depletion of immature neuronal populations in the OB and DG. Once ablated, progenitor proliferation was slow to recover even in the absence of continuing GCV administration, and the rate of recovery differed among the neurogenic regions. Two weeks after the cessation of GCV infusion, proliferation recovered in the SVZ but not the SGZ, and no immature neurons were evident in the $O B$ or DG. After an extended recovery period of 6 weeks, both proliferation and immature neurons were present bilaterally in the SVZ/OB pathway, but the SGZ/DG pathway experienced only a partial, unilateral recovery. These results suggest that the dynamics of progenitor proliferation differ significantly among the SVZ and SGZ, although the nature of these differences remains to be determined.

\section{The nestin-tk mouse permits inducible ablation of adult neurogenesis}

We sought to produce a model system to facilitate the study of adult neurogenesis and its role in neurophysiology and behavior. Undesired systemic toxicity is a problem common to the GFAP-tk mouse, which utilizes thymidine kinase expression to ablate GFAP-expressing neural progenitors (Bush et al., 1998; Morshead et al., 2003; Garcia et al., 2004), and the nestin-tk mouse. Here, we overcame this obstacle by infusing GCV directly into the lateral ventricle, maximizing GCV administration to the brain while minimizing systemic exposure. This approach allowed us to deliver GCV continuously for 28 days without morbidity, facilitating a near-complete ablation of adult neurogenesis. The need for implantation surgery is a disadvantage of our model, and a small percentage of animals had to be excluded due to surgical complications that included infection and hemorrhage. However, in the vast majority we found no adverse effects of the surgery and chronic infusion on activity and behavior, including the tail suspension behavioral task used in this study.

Antimitotic agents (Doetsch et al., 1999; Shors et al., 2002), x-irradiation (Mizumatsu et al., 2003), and transgenic expression of thymidine kinase under the GFAP promoter (Bush et al., 1999; Garcia et al., 2004) have all been employed with success to reduce or eliminate adult neurogenesis. These approaches all act on nonneuronal cell populations as well, and in particular alter the brain's response to injury. Whereas we focused on the ablation and recovery of immature neurons, other studies utilizing the nestin 2 nd intronic enhancer to drive a reporter gene suggest that this regulatory element drives only constitutive neurogenesis and does not play a role in the injury response (Johansson et al., 2002). Thus, the nestin-tk mouse may be a fruitful tool for the study of both the normal physiological roles of neurogenesis and the function of neurogenesis in neurologic disease and brain injury.

\section{Reconstitution of neurogenesis after ablation in the SVZ and SGZ}

Progenitors in the SVZ and SGZ are normally maintained in a quiescent state by signals within the stem cell niche (Ahn and Joyner, 2005). Ablating the actively dividing fraction of the 

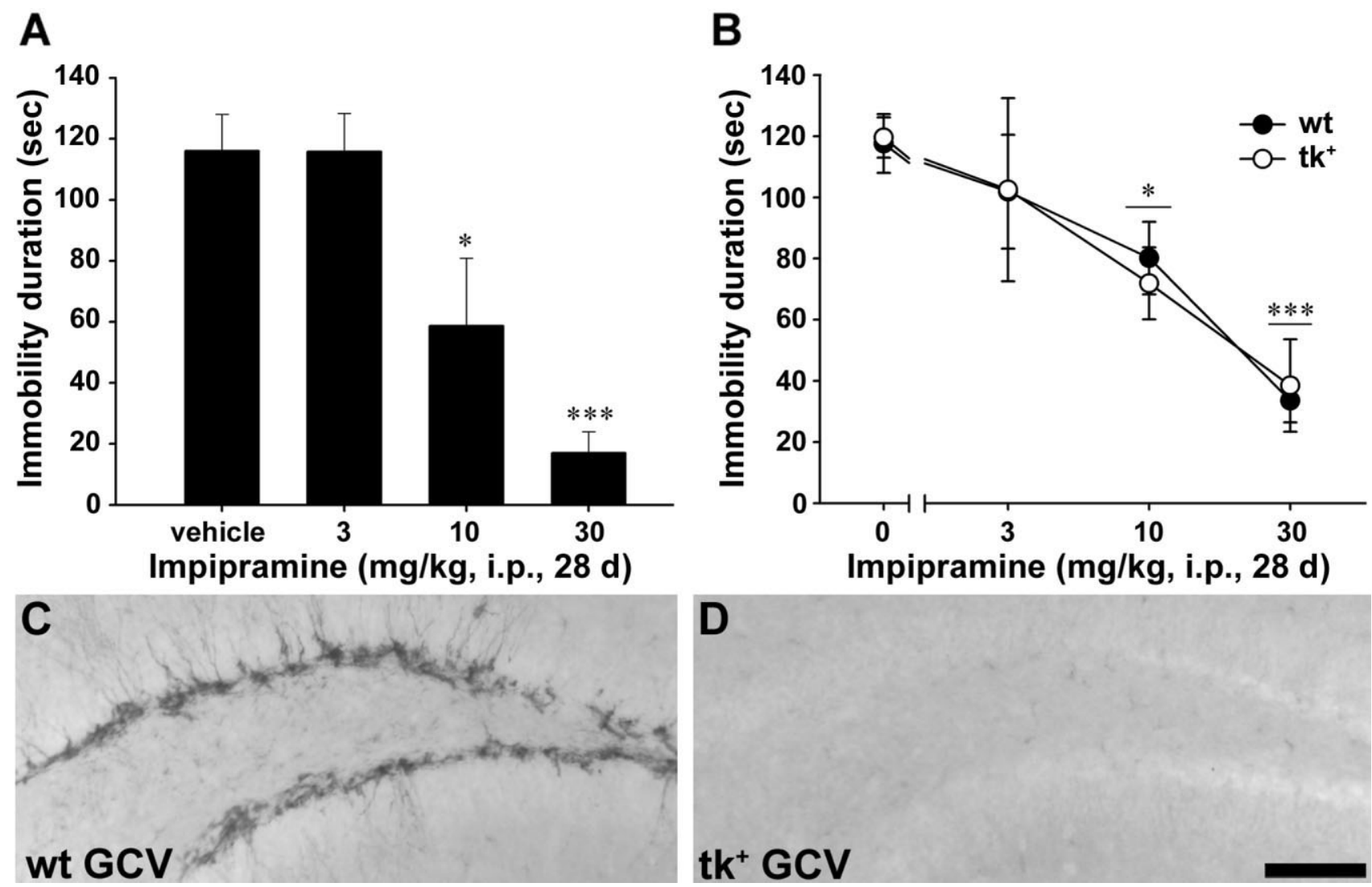

Figure 8.

A,B: Imipramine produced antidepressant-like effects in the tail suspension test in nonimplanted FVB mice (A) and in ganciclovir (GCV)-treated wild-type (wt) and nestin-tk ${ }^{+}\left(\mathrm{tk}^{+}\right)$mice (B). In nonimplanted FVB mice (A), 28-day administration of imipramine (i.p.) produced dose-dependent decreases in immobility with significant reductions observed at 10 and $30 \mathrm{mg} / \mathrm{kg}$. Similarly, chronic administration of 10 and $30 \mathrm{mg} / \mathrm{kg}$ imipramine significantly decreased immobility in the tail suspension test in GCV-treated wild-type and nestin-tk ${ }^{+}$mice (B); however, there was no significant difference between wild-type and nestin-tk ${ }^{+}$mice. *,$P<0.05$ compared with vehicle $\left(0 \mathrm{mg} / \mathrm{kg}\right.$ imipramine) and ${ }^{* *}, P<0.001 \mathrm{compared}$ with vehicle $(0 \mathrm{mg} / \mathrm{kg}$ imipramine) as determined by one- or two-way ANOVA with Dunnett's post hoc tests. C,D: Doublecortin immunostaining of representative sections from GCV-treated wild-type (C) and nestin-tk ${ }^{+}$mice (D) used in the depression studies. The transgenic mouse shows complete loss of immature neurons (D), whereas the wild-type littermate maintains robust labeling (E). Scale bar $=100 \mu \mathrm{m}$ in D (applies to C,D).

stem cell population, however, leads normally quiescent progenitors to enter the cell cycle (Doetsch et al., 1999; Seri et al., $2001,2004)$. When proliferating cells in the SVZ and SGZ are eliminated with a brief antimitotic treatment, these newly active progenitors rapidly repopulate the SVZ/OB and SGZ/DG pathways (Doetsch et al., 1999; Seri et al., 2004). Here, however, we delivered GCV for 28 days, ablating successive fractions of the progenitor population as they became active.

Nevertheless, the limited recovery of neurogenesis we observed in both the SVZ and SGZ indicates that some progenitor cells do escape ablation, even after 28 days of GCV treatment. The persistence of radial glia-like cells in the DG after GCV treatment suggests that a subset of type 1 stem-like cells may stop proliferating and thereby avoid GCV-induced death. Also, the asymmetric recovery between ipsilateral and contralateral DG likely resulted from the latter being exposed to a lower GCV concentration, leading to greater recovery, whereas the ipsilateral DG was exposed to higher GCV concentrations similar to those that would be expected in the SVZ after ICV infusion. The greater recovery seen in the SVZ than ipsilateral SGZ suggests that many SGZ progenitors more readily enter the cell cycle and are thus more vulnerable to elimination than their counterparts in the SVZ. Alternatively, the remaining progenitors in the SVZ could proliferate at a higher rate than in the SGZ, leading to faster SVZ recovery. However, unlike mice treated with irradiation to eliminate the cohort of actively dividing cells who then experience a surge in compensatory proliferation in the SVZ (Tada et al., 1999), nestin-tk ${ }^{+}$mice seem to possess a limited regenerative capacity and repopulate the neurogenic zones more gradually. $A$ third possibility is that thymidine kinase is incompletely expressed in both progenitor populations, and differentially expressed in the SVZ and SGZ. The complete lack of neurogenesis in nestin-tk ${ }^{+}$mice 2 weeks after the cessation of GCV infusion, however, argues against a scenario in which a subpopulation of actively dividing progenitors escapes ablation throughout the period of GCV administration.

\section{Role of neurogenesis in antidepressant-like effects}

One current theory proposes that hippocampal cell proliferation and neurogenesis are the common therapeutic mechanisms of all known classes of antidepressant drugs. We 
therefore used our model system to test whether suppressing neurogenesis alters the actions of antidepressants following chronic administration. After daily imipramine administration for 4 weeks, GCV-treated wild-type and nestin-tk ${ }^{+}$mice demonstrated similar antidepressant-like effects in the mouse tail suspension test. Overall, these data suggest that neurogenesis is not required for the antidepressant actions of imipramine as measured in the tail suspension model.

Our findings are consistent with some studies demonstrating that chronic antidepressant treatment did not increase neurogenesis and that $x$-irradiation of the hippocampus did not alter the antidepressant effects of fluoxetine (Meshi et al., 2006; Holick et al., 2008; Huang et al., 2008; Surget et al., 2008). However, other studies reported that proliferation was reduced in animal models of depression, but that chronic antidepressant treatment reversed this decrement (Kodama et al., 2004; Bjornebekk et al., 2005; Chen et al., 2006; JaakoMovits et al., 2006; Lau et al., 2007; Perera et al., 2007; Qiu et al., 2007; Marcussen et al., 2008; Warner-Schmidt et al., 2008). Likewise, ablation of neurogenesis by $x$-irradiation of the hippocampus eliminated the proliferation-promoting effects of fluoxetine and imipramine and prevented their antidepressantlike activity as measured in the novelty-suppressed feeding paradigm and chronic unpredictable stress model of depression (Santarelli et al., 2003; Surget et al., 2008). Together, these data suggest that the role of adult neurogenesis in depression-related behaviors and antidepressant actions remains to be determined, and that further investigation is needed to understand better the biology of adult-born neurons.

In addition to its usefulness in studying the role of adult neurogenesis in depression, the nestin-tk mouse offers utility for investigating the functions of adult-born neurons in hippocampal physiology, other behavioral paradigms, and neurological disease models. Furthermore, because the loss of adult-born neurons is not irreversible, this model system will facilitate future investigations of how the neurogenic niche is reconstituted after an insult, such as treatment of brain malignancies (Monje et al., 2007). Further studies using this mouse will enhance our understanding, not only of the functional role of adult neurogenesis in the brain, but also of the basic dynamics underlying the birth, survival, and death of adult-born neurons.

\section{ACKNOWLEDGMENTS}

The authors thank Greg Sturgeon, Nidhi Maley, and Puneet Sodhi for technical assistance, Henry Paulson for assistance with stereology equipment, and K. Sue O'Shea for helpful discussions during the conception of this project.

\section{LITERATURE CITED}

Ahn S, Joyner AL. 2005. In vivo analysis of quiescent adult neural stem cells responding to Sonic hedgehog. Nature 437:894-897.

Alonso M, Viollet C, Gabellec MM, Meas-Yedid V, Olivo-Marin JC, Lledo PM. 2006. Olfactory discrimination learning increases the survival of adult-born neurons in the olfactory bulb. J Neurosci 26:10508-10513.

Altman J. 1969a. Autoradiographic and histological studies of postnatal neurogenesis. 3. Dating the time of production and onset of differentiation of cerebellar microneurons in rats. J Comp Neurol 136:269-293.

Altman J. 1969b. Autoradiographic and histological studies of postnata neurogenesis. IV. Cell proliferation and migration in the anterior forebrain, with special reference to persisting neurogenesis in the olfactory bulb. J Comp Neurol 137:433-457.
Altman J, Das GD. 1965. Autoradiographic and histological evidence of postnatal hippocampal neurogenesis in rats. J Comp Neurol 124:319335.

Balzarini J, Degreve B, Andrei G, Neyts J, Sandvold M, Myhren F, de Clercq E. 1998. Superior cytostatic activity of the ganciclovir elaidic acid ester due to the prolonged intracellular retention of ganciclovir anabolites in herpes simplex virus type 1 thymidine kinase genetransfected tumor cells. Gene Ther 5:419-426.

Bermejo PE, Jimenez CE, Torres CV, Avendano C. 2003. Quantitative stereological evaluation of the gracile and cuneate nuclei and their projection neurons in the rat. J Comp Neurol 463:419-433.

Bjornebekk A, Mathe AA, Brene S. 2005. The antidepressant effect of running is associated with increased hippocampal cell proliferation. Int J Neuropsychopharmacol 8:357-368.

Bodor N, Buchwald P. 1999. Recent advances in the brain targeting of neuropharmaceuticals by chemical delivery systems. Adv Drug Delivery Rev 36:229-254.

Brown JP, Couillard-Despres S, Cooper-Kuhn CM, Winkler J, Aigner L, Kuhn HG. 2003. Transient expression of doublecortin during adult neurogenesis. J Comp Neurol 467:1-10.

Bush TG, Savidge TC, Freeman TC, Cox HJ, Campbell EA, Mucke L, Johnson MH, Sofroniew MV. 1998. Fulminant jejuno-ileitis following ablation of enteric glia in adult transgenic mice. Cell 93:189-201.

Bush TG, Puvanachandra N, Horner CH, Polito A, Ostenfeld T, Svendsen CN, Mucke L, Johnson MH, Sofroniew MV. 1999. Leukocyte infiltration, neuronal degeneration, and neurite outgrowth after ablation of scarforming, reactive astrocytes in adult transgenic mice. Neuron 23:297308.

Cameron HA, Woolley CS, McEwen BS, Gould E. 1993. Differentiation of newly born neurons and glia in the dentate gyrus of the adult rat. Neuroscience 56:337-344.

Chen H, Pandey GN, Dwivedi Y. 2006. Hippocampal cell proliferation regulation by repeated stress and antidepressants. Neuroreport 17 863-867.

Cheng YC, Huang ES, Lin JC, Mar EC, Pagano JS, Dutschman GE, Grill SP. 1983. Unique spectrum of activity of 9-[(1,3-dihydroxy-2propoxy)methyl]-guanine against herpesviruses in vitro and its mode of action against herpes simplex virus type 1. Proc Natl Acad Sci U S A 80:2767-2770.

Corotto FS, Henegar JR, Maruniak JA. 1994. Odor deprivation leads to reduced neurogenesis and reduced neuronal survival in the olfactory bulb of the adult mouse. Neuroscience 61:739-744.

Couillard-Despres S, Winner B, Schaubeck S, Aigner R, Vroemen M, Weidner N, Bogdahn U, Winkler J, Kuhn HG, Aigner L. 2005. Doublecortin expression levels in adult brain reflect neurogenesis. Eur J Neurosci 21:1-14.

da Silva RP, Gordon S. 1999. Phagocytosis stimulates alternative glycosylation of macrosialin (mouse CD68), a macrophage-specific endosomal protein. Biochem J 338:687-694.

Doetsch F, Garcia-Verdugo JM, Alvarez-Buylla A. 1999. Regeneration of a germinal layer in the adult mammalian brain. Proc Natl Acad Sci U S A 96:11619-11624.

Elder GA, De Gasperi R, Gama Sosa MA. 2006. Research update: neurogenesis in adult brain and neuropsychiatric disorders. Mt Sinai J Med 73:931-940.

Enwere E, Shingo T, Gregg C, Fujikawa H, Ohta S, Weiss S. 2004. Aging results in reduced epidermal growth factor receptor signaling, diminished olfactory neurogenesis, and deficits in fine olfactory discrimination. J Neurosci 24:8354-8365.

Eriksson PS, Perfilieva E, Bjork-Eriksson T, Alborn AM, Nordborg C, Peterson DA, Gage FH. 1998. Neurogenesis in the adult human hippocampus. Nat Med 4:1313-1317.

Ernst C, Christie BR. 2005. Nestin-expressing cells and their relationship to mitotically active cells in the subventricular zones of the adult rat. Eur J Neurosci 22:3059-3066.

Garcia AD, Doan NB, Imura T, Bush TG, Sofroniew MV. 2004. GFAPexpressing progenitors are the principal source of constitutive neurogenesis in adult mouse forebrain. Nat Neurosci 7:1233-1241.

Ge S, Sailor KA, Ming GL, Song H. 2008. Synaptic integration and plasticity of new neurons in the adult hippocampus. J Physiol 586:37593765 .

Gheusi G, Lledo PM. 2007. Control of early events in olfactory processing by adult neurogenesis. Chem Senses 32:397-409.

Gheusi G, Cremer H, McLean H, Chazal G, Vincent JD, Lledo PM. 2000. 
Importance of newly generated neurons in the adult olfactory bulb for odor discrimination. Proc Natl Acad Sci U S A 97:1823-1828.

Gould E, Woolley CS, McEwen BS. 1991. Adrenal steroids regulate postnatal development of the rat dentate gyrus: I. Effects of glucocorticoids on cell death. J Comp Neurol 313:479-485.

Gould E, McEwen BS, Tanapat P, Galea LA, Fuchs E. 1997. Neurogenesis in the dentate gyrus of the adult tree shrew is regulated by psychosocial stress and NMDA receptor activation. J Neurosci 17:2492-2498.

Gritti A, Parati EA, Cova L, Frolichsthal P, Galli R, Wanke E, Faravelli L, Morassutti DJ, Roisen F, Nickel DD, Vescovi AL. 1996. Multipotential stem cells from the adult mouse brain proliferate and self-renew in response to basic fibroblast growth factor. J Neurosci 16:1091-1100.

Gundersen HJ, Jensen EB, Kieu K, Nielsen J. 1999. The efficiency of systematic sampling in stereology-reconsidered. J Microsc 193:199211.

Heyman RA, Borrelli E, Lesley J, Anderson D, Richman DD, Baird SM, Hyman R, Evans RM. 1989. Thymidine kinase obliteration: creation of transgenic mice with controlled immune deficiency. Proc Natl Acad Sci U S A 86:2698-2702.

Hockfield S, McKay RD. 1985. Identification of major cell classes in the developing mammalian nervous system. J Neurosci 5:3310-3328.

Holick KA, Lee DC, Hen R, Dulawa SC. 2008. Behavioral effects of chronic fluoxetine in BALB/cJ mice do not require adult hippocampal neurogenesis or the serotonin $1 \mathrm{~A}$ receptor. Neuropsychopharmacology 33 406-417.

Huang GJ, Bannerman D, Flint J. 2008. Chronic fluoxetine treatment alters behavior, but not adult hippocampal neurogenesis, in BALB/cJ mice. Mol Psychiatry 13:119-121.

Jaako-Movits K, Zharkovsky T, Pedersen M, Zharkovsky A. 2006. Decreased hippocampal neurogenesis following olfactory bulbectomy is reversed by repeated citalopram administration. Cell Mol Neurobiol 26:1559-1570.

Johansson CB, Lothian C, Molin M, Okano H, Lendahl U. 2002. Nestin enhancer requirements for expression in normal and injured adult CNS. J Neurosci Res 69:784-794.

Kempermann G, Gast D, Gage FH. 2002. Neuroplasticity in old age: sustained fivefold induction of hippocampal neurogenesis by long term environmental enrichment. Ann Neurol 52:135-143.

Key G, Becker MH, Baron B, Duchrow M, Schluter C, Flad HD, Gerdes J. 1993a. New Ki-67-equivalent murine monoclonal antibodies (MIB 1-3) generated against bacterially expressed parts of the Ki-67 cDNA containing three 62 base pair repetitive elements encoding for the Ki-67 epitope. Lab Invest 68:629-636.

Key G, Petersen JL, Becker MH, Duchrow M, Schluter C, Askaa J, Gerdes J. 1993b. New antiserum against Ki-67 antigen suitable for double immunostaining of paraffin wax sections. J Clin Pathol 46:1080-1084.

Kodama M, Fujioka T, Duman RS. 2004. Chronic olanzapine or fluoxetine administration increases cell proliferation in hippocampus and prefrontal cortex of adult rat. Biol Psychiatry 56:570-580.

Koizumi H, Higginbotham H, Poon T, Tanaka T, Brinkman BC, Gleeson JG. 2006. Doublecortin maintains bipolar shape and nuclear translocation during migration in the adult forebrain. Nat Neurosci 9:779-786.

Kuhn HG, Dickinson-Anson H, Gage FH. 1996. Neurogenesis in the dentate gyrus of the adult rat: age-related decrease of neuronal progenitor proliferation. J Neurosci 16:2027-2033.

Latov N, Nilaver G, Zimmerman EA, Johnson WG, Silverman AJ, Defendin R, Cote L. 1979. Fibrillary astrocytes proliferate in response to brain injury: a study combining immunoperoxidase technique for glial fibrillary acidic protein and radioautography of tritiated thymidine. Dev Biol 72:381-384.

Lau WM, Qiu G, Helmeste DM, Lee TM, Tang SW, So KF. 2007. Corticosteroid decreases subventricular zone cell proliferation, which could be reversed by paroxetine. Restor Neurol Neurosci 25:17-23.

Lichtenwalner RJ, Parent JM. 2006. Adult neurogenesis and the ischemic forebrain. J Cereb Blood Flow Metab 26:1-20.

Lledo PM, Lagier S. 2006. Adjusting neurophysiological computations in the adult olfactory bulb. Semin Cell Dev Biol 17:443-453.

Lois C, Alvarez-Buylla A. 1994. Long-distance neuronal migration in the adult mammalian brain. Science 264:1145-1148.

Luskin MB. 1993. Restricted proliferation and migration of postnatally generated neurons derived from the forebrain subventricular zone. Neuron 11:173-189.

Luskin MB. 1998. Neuroblasts of the postnatal mammalian forebrain: their phenotype and fate. J Neurobiol 36:221-233.

Magavi SS, Mitchell BD, Szentirmai O, Carter BS, Macklis JD. 2005.
Adult-born and preexisting olfactory granule neurons undergo distinct experience-dependent modifications of their olfactory responses in vivo. J Neurosci 25:10729-10739.

Mandairon N, Jourdan F, Didier A. 2003. Deprivation of sensory inputs to the olfactory bulb up-regulates cell death and proliferation in the subventricular zone of adult mice. Neuroscience 119:507-516.

Mandairon N, Sacquet J, Garcia S, Ravel N, Jourdan F, Didier A. 2006a Neurogenic correlates of an olfactory discrimination task in the adult olfactory bulb. Eur J Neurosci 24:3578-3588.

Mandairon N, Sacquet J, Jourdan F, Didier A. 2006b. Long-term fate and distribution of newborn cells in the adult mouse olfactory bulb: Influences of olfactory deprivation. Neuroscience 141:443-451.

Marcussen AB, Flagstad P, Kristjansen PE, Johansen FF, Englund U. 2008. Increase in neurogenesis and behavioural benefit after chronic fluoxetine treatment in Wistar rats. Acta Neurol Scand 117:94-100.

Maslov AY, Barone TA, Plunkett RJ, Pruitt SC. 2004. Neural stem cel detection, characterization, and age-related changes in the subventricular zone of mice. J Neurosci 24:1726-1733.

Meshi D, Drew MR, Saxe M, Ansorge MS, David D, Santarelli L, Malapan C, Moore H, Hen R. 2006. Hippocampal neurogenesis is not required for behavioral effects of environmental enrichment. Nat Neurosci 9:729-731.

Ming GL, Song H. 2005. Adult neurogenesis in the mammalian central nervous system. Annu Rev Neurosci 28:223-250.

Mizumatsu S, Monje ML, Morhardt DR, Rola R, Palmer TD, Fike JR. 2003. Extreme sensitivity of adult neurogenesis to low doses of $\mathrm{X}$-irradiation. Cancer Res 63:4021-4027.

Monje ML, Vogel H, Masek M, Ligon KL, Fisher PG, Palmer TD. 2007. Impaired human hippocampal neurogenesis after treatment for central nervous system malignancies. Ann Neurol 62:515-520.

Morshead CM, Garcia AD, Sofroniew MV, van Der Kooy D. 2003. The ablation of glial fibrillary acidic protein-positive cells from the adult central nervous system results in the loss of forebrain neural stem cells but not retinal stem cells. Eur J Neurosci 18:76-84.

Mullen RJ, Buck CR, Smith AM. 1992. NeuN, a neuronal specific nuclear protein in vertebrates. Development (Cambridge, England) 116:201211.

Perera TD, Coplan JD, Lisanby SH, Lipira CM, Arif M, Carpio C, Spitzer G, Santarelli L, Scharf B, Hen R, Rosoklija G, Sackeim HA, Dwork AJ. 2007. Antidepressant-induced neurogenesis in the hippocampus of adult nonhuman primates. J Neurosci 27:4894-4901.

Qiu G, Helmeste DM, Samaranayake AN, Lau WM, Lee TM, Tang SW, So KF. 2007. Modulation of the suppressive effect of corticosterone on adult rat hippocampal cell proliferation by paroxetine. Neurosci Bull 23:131-136.

Reynolds BA, Weiss S. 1992. Generation of neurons and astrocytes from isolated cells of the adult mammalian central nervous system. Science 255:1707-1710.

Rochefort C, Lledo PM. 2005. Short-term survival of newborn neurons in the adult olfactory bulb after exposure to a complex odor environment. Eur J Neurosci 22:2863-2870.

Rochefort C, Gheusi G, Vincent JD, Lledo PM. 2002. Enriched odor exposure increases the number of newborn neurons in the adult olfactory bulb and improves odor memory. J Neurosci 22:2679-2689.

Santarelli L, Saxe M, Gross C, Surget A, Battaglia F, Dulawa S, Weisstaub N, Lee J, Duman R, Arancio O, Belzung C, Hen R. 2003. Requirement of hippocampal neurogenesis for the behavioral effects of antidepressants. Science 301:805-809.

Saxe MD, Battaglia F, Wang JW, Malleret G, David DJ, Monckton JE, Garcia AD, Sofroniew MV, Kandel ER, Santarelli L, Hen R, Drew MR. 2006. Ablation of hippocampal neurogenesis impairs contextual fear conditioning and synaptic plasticity in the dentate gyrus. Proc Nat Acad Sci U S A 103:17501-17506.

Saxe MD, Malleret G, Vronskaya S, Mendez I, Garcia AD, Sofroniew MV, Kandel ER, Hen R. 2007. Paradoxical influence of hippocampal neurogenesis on working memory. Proc Natl Acad Sci U S A 104:46424646.

Schellinck HM, Arnold A, Rafuse VF. 2004. Neural cell adhesion molecule (NCAM) null mice do not show a deficit in odour discrimination learning. Behav Brain Res 152:327-334.

Schmidt HD, Duman RS. 2007. The role of neurotrophic factors in adult hippocampal neurogenesis, antidepressant treatments and animal models of depressive-like behavior. Behav Pharmacol 18:391-418.

Seaberg RM, van der Kooy D. 2002. Adult rodent neurogenic regions: the 
ventricular subependyma contains neural stem cells, but the dentate gyrus contains restricted progenitors. J Neurosci 22:1784-1793.

Seri B, Garcia-Verdugo JM, McEwen BS, Alvarez-Buylla A. 2001. Astrocytes give rise to new neurons in the adult mammalian hippocampus. J Neurosci 21:7153-7160.

Seri B, Garcia-Verdugo JM, Collado-Morente L, McEwen BS, AlvarezBuylla A. 2004. Cell types, lineage, and architecture of the germinal zone in the adult dentate gyrus. J Comp Neurol 478:359-378.

Shors TJ, Miesegaes G, Beylin A, Zhao M, Rydel T, Gould E. 2001. Neurogenesis in the adult is involved in the formation of trace memories. Nature 410:372-376.

Shors TJ, Townsend DA, Zhao M, Kozorovitskiy Y, Gould E. 2002. Neurogenesis may relate to some but not all types of hippocampaldependent learning. Hippocampus 12:578-584.

Smoak IW, Branch S. 2000. Glut-1 expression and its response to hypoglycemia in the embryonic mouse heart. Anat Embryol 201:327-333.

Snyder JS, Kee N, Wojtowicz JM. 2001. Effects of adult neurogenesis on synaptic plasticity in the rat dentate gyrus. J Neurophysiol 85:24232431.

Surget A, Saxe M, Leman S, Ibarguen-Vargas Y, Chalon S, Griebel G, Hen $R$, Belzung C. 2008. Drug-dependent requirement of hippocampa neurogenesis in a model of depression and of antidepressant reversal. Biol Psychiatry 64:293-301.

Tada E, Yang C, Gobbel GT, Lamborn KR, Fike JR. 1999. Long-term impairment of subependymal repopulation following damage by ionizing irradiation. Exp Neurol 160:66-77.
Tropepe V, Sibilia M, Ciruna BG, Rossant J, Wagner EF, van der Kooy D. 1999. Distinct neural stem cells proliferate in response to EGF and FGF in the developing mouse telencephalon. Dev Biol 208:166-188.

van Praag H, Kempermann G, Gage FH. 1999. Running increases cell proliferation and neurogenesis in the adult mouse dentate gyrus. Nat Neurosci 2:266-270.

Vanderlaan M, Thomas CB. 1985. Characterization of monoclonal antibodies to bromodeoxyuridine. Cytometry 6:501-505.

Wang TW, Zhang H, Parent JM. 2005. Retinoic acid regulates postnata neurogenesis in the murine subventricular zone-olfactory bulb pathway. Development (Cambridge, England) 132:2721-2732.

Warner-Schmidt JL, Madsen TM, Duman RS. 2008. Electroconvulsive seizure restores neurogenesis and hippocampus-dependent fear memory after disruption by irradiation. Eur J Neurosci 27:1485-1493.

West MJ, Slomianka L, Gundersen HJ. 1991. Unbiased stereological estimation of the total number of neurons in thesubdivisions of the rat hippocampus using the optical fractionator. Anat Rec 231:482-497.

Yamaguchi M, Saito H, Suzuki M, Mori K. 2000. Visualization of neurogenesis in the central nervous system using nestin promoter-GFP transgenic mice. Neuroreport 11:1991-1996.

Yaworsky PJ, Kappen C. 1999. Heterogeneity of neural progenitor cells revealed by enhancers in the nestin gene. Dev Biol 205:309-321.

Zhang CL, Zou Y, He W, Gage FH, Evans RM. 2008. A role for adult TLX-positive neural stem cells in learning and behaviour. Nature 451 : 1004-1007. 